San Jose State University

SJSU ScholarWorks

Master's Theses

Master's Theses and Graduate Research

1991

\title{
An exploratory study of the effects of intergenerational communication and elderly talk regarding the past, present, and future
}

Susan Kristen Taylor

San Jose State University

Follow this and additional works at: https://scholarworks.sjsu.edu/etd_theses

\section{Recommended Citation}

Taylor, Susan Kristen, "An exploratory study of the effects of intergenerational communication and elderly talk regarding the past, present, and future" (1991). Master's Theses. 220.

DOI: https://doi.org/10.31979/etd.87hc-ey3q

https://scholarworks.sjsu.edu/etd_theses/220

This Thesis is brought to you for free and open access by the Master's Theses and Graduate Research at SJSU ScholarWorks. It has been accepted for inclusion in Master's Theses by an authorized administrator of SJSU ScholarWorks. For more information, please contact scholarworks@sjsu.edu. 


\section{INFORMATION TO USERS}

This manuscript has been reproduced from the microfilm master. UMI films the text directly from the original or copy submitted. Thus, some thesis and dissertation copies are in typewriter face, while others may be from any type of computer printer.

The quality of this reproduction is dependent upon the quality of the copy submitted. Broken or indistinct print, colored or poor quality illustrations and photographs, print bleedthrough, substandard margins, and improper alignment can adversely affect reproduction.

In the unlikely event that the author did not send UMI a complete manuscript and there are missing pages, these will be noted. Also, if unauthorized copyright material had to be removed, a note will indicate the deletion.

Oversize materials (e.g., maps, drawings, charts) are reproduced by sectioning the original, beginning at the upper left-hand corner and continuing from left to right in equal sections with small overlaps. Each original is also photographed in one exposure and is included in reduced form at the back of the book.

Photographs included in the original manuscript have been reproduced xerographically in this copy. Higher quality $6 " \mathrm{x}$ 9" black and white photographic prints are available for any photographs or illustrations appearing in this copy for an additional charge. Contact UMI directly to order.

\section{$\mathrm{U} \cdot \mathrm{M} \cdot \mathrm{I}$}

University Microfilms International

A Bell \& Howell information Company 300 North Zeeb Road. Ann Arbor. MI 48106-1346 USA

$313,761-4700 \quad 800 ; 521-0600$ 
- . . . . . . 
Order Number 1345827

An exploratory study of the effects of intergenerational communication and elderly talk regarding the past, present, and future

Taylor, Susan Kristen, M.A.

San Jose State University, 1991

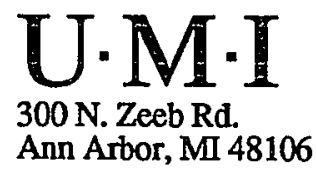


- 


\begin{abstract}
AN EXPLORATORY STUDY OF
THE EFFECTS OF INTERGENERATIONAL COMMUNICATION

AND ELDERLY TALK REGARDING THE PAST, PRESENT, AND FUTURE
\end{abstract}

\begin{abstract}
A Thesis
Presented to

The Faculty of the Department of Communication studies San Jose state University
\end{abstract}

In Partial Fulfillment

of the Requirements for the Degree

Master of Arts

By

Susan Kristen Taylor

August, 1991 
APPROVED FOR THE DEPARTMENT OF COMMUNICATION STUDIES

Dr. Wen-shu Lee

Whaid/d. Elater

Dr. David Elliott

Pretor ofunoluser

Dr. Milton Anderson

APPROVED FOR THE UNIVERSITY

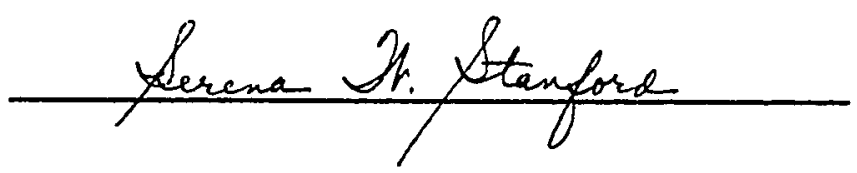




\begin{abstract}
AN EXPLORATORY STUDY OF

THE EFFECTS OF INTERGENERATIONAL COMMUNICATION

AND ELDERLY TALK REGARDING THE PAST, PRESENT, AND FUTURE

by Susan Kristen Taylor

Two separate studies were conducted to examine

attitudes toward aging and the elderly. Interviews were

conducted on children ( $\underline{N}=43$ ) from an intergenerational day

care center and conventional day care centers using two

revised subtests of the Children's Attitudes Toward the

Elderly instrument (CATE). The results indicated that there

were no significant difference between the two groups of

children regarding attitudes toward aging and the elderly.

However, additional findings suggest that preschool children

do not have a conceptual understanding of aging.

The second study explored elderly people's talk about

the past, present, and future in relation to life

satisfaction, perceived contribution, and functions of

reminiscence. Volunteers $(\underline{\mathbb{N}}=66)$ completed self-report

questionnaires derived from the Life Satisfaction Index

(ISIA) and the Questionnaire on Reminiscence. Results

indicated that talking about the past serves several

reminiscence functions, but talking about the present, and

Euture are predictors of life satisfaction and perceived

contribution.
\end{abstract}




\section{ACKNOWLEDGEMENTS}

As I reflect upon the countless hours it took to achieve this thesis, I cannot help but think of all the support I received to make this research possible. Individuals from several generations were willing to contribute their time and effort to this project. I truly must thank all the little people, and the not so little people that helped me reach this goal.

I want to thank my family, who never gave up on me. I am so fortunate to have Ron and Rose Taylor as my parents. If it was not for their emotional and financial support, I would never have been able to continue my education. I can honestly say they are my best friends. My sisters sara and stacey were very helpful in getting me through some stressful times. They always knew when "not" to ask me about my thesis. My grandparents Vern and Katy Taylor, and my aunt Janice wilkerson were a great help to me in collecting the data for the elderly study. Their willingness to participate really touched my heart.

My heart is filled with gratitude towards another special person. Wen-shu Lee, my advisor, has supported me every step of the way. She has taught me more about research than anyone I have ever known. Her knowledge and experience has helped me grow. Without her, this thesis would never have been written. I am so fortunate to have her as a mentor and a close friend. 
My committee members also enriched this thesis with their wisdom. David Elliott provided me with valuable feedback. His suggestions improved the final drafts of my thesis. His empathy during stressful moments was also appreciated. Bud Anderson provided some interesting insight to the thesis. I know he will continue to share his knowledge long after his retirement.

Several friends also need to be recognized for their contribution to this thesis. My roommate Sharon Henry was very supportive in times of confusion. Our late night discussions helped me solve some difficult problems. Martin King was also infamous for helping me cope with life's pressures. My colleague Bob Funk rearranged his teaching schedule, so I could have more time to work on my thesis. Kris Adams and Rob Dewis provided me with teaching materials when I had less time to focus on developing my classes. I want to thank my friend, and former English Professor Jean Burrows. Her reviews of the thesis improved it immensely. She also had a strong shoulder to lean on in times of chaos. Thanks need to be given to those people that participated in various stages of the studies. Tracy soper, Jean Abernathy, and Karen Sammann were a tremendous help on the coding. I am grateful to Ann Corona-Torres, Wanda Henry, and the many day care assistants for their patience, understanding, and interest in my thesis. I also want to extend my gratitude to all the elderly people who took the 
time to complete the questionnaire.

Finally, I want to thank all the little people. One of the most enjoyable parts of this research was talking to the children from the different day care centers. I will always remember the children who shared their experiences, lunches, and even their toys with me. 
TABLE OF CONTENTS

Page

ACKNOWLEDGEMENTS . . . . . . . . . . . . . . . IV

LIST OF TABLES . . . . . . . . . . . . . . . . . . vii v vi

Chapter

I. INTRODUCTION AND REVIEW OF LITERATURE . . . . 1

Attitudes Toward Aging and the Elderly . . 2

Reminiscence . . . . . . . . . . 6

Theoretical Approaches to Aging . . . . . 9

Intergenerational Programs . . . . . . 14

Research Questions . . . . . . . . . 19

I I. METHODS . . . . . . . . . . . . . . . . 20

study I . . . . . . . . . . . . . . . 20

subjects . . . . . . . . . . . 20

Measurements . . . . . . . . . . 21

Pretest . . . . . . . . . . 24

Procedures . . . . . . . . . . 26

Studỹ II . . . . . . . . . . . . . 27

subjects . . . . . . . . . . 27

Measurements . . . . . . . . 28

Pretest . . . . . . . . . . . 31

Procedures . . . . . . . . . . 31

III. DATA ANALYSIS . . . . . . . . . . . . . 33

study I . . . . . . . . . . . . . 33

CATE Coding . . . . . . . . . 33

Chi-square Analysis of Responses to

CATE . . . . . . . . . . . . 
Study II . . . . . . . . . . . . . 52

Recode and Reliability . . . . . 52

Principal Component Analyses . . . 53

Regression Analyses . . . . . . . 65

IV. RESULTS AND DISCUSSION . . . . . . . . . . . 68

study I . . . . . . . . . . . . . 68

study II . . . . . . . . . . . . . 73

Overall Conclusions . . . . . . . . 75

Limitations . . . . . . . . . 75

Recommendations for Further Research 77

REFERENCES • . • • • • . . . • . . . . . . . 79

ARPENDIXES . . . . . . . . . . . . . . . . . . 86

A. Original CATE Questionnaire and Categories . . 87

B. Revised CATE Questionnaire . . . . . . . . 92

C. Revised Photographs for Picture Questions . . 95

D. Revised Elderly Questionnaire . . . . . . . 97

E. Revised CATE Coding Categories and Definitions 110 


\section{LIST OF TABLES}

TABLES

Page

1. Definitions of Variables for Picture Questions and Word Association Questions . . . . 46

2. Inter-coder Reliability Coefficients for Picture subtest and word Association Categories . . . . . . . . . . . . . . 4 47

3. Past, Present, and Future Talk Items . . . . . 54

4. Factor Analysis of Past, Present, and Future Talk Items... . . . . . . . . . . . . . 54

5. Factor Matrix of Talk Items . . . . . . . . 54

6. Perceived Contribution Items . . . . . . . . 55

7. Factor Analysis of Perceived Contribution Items . . . . . . . . . . . . . . . . . 55

8. Rotated Factor of Perceived Contribution Items . . . . . . . . . . . . . . . . 56

9. Deleted Life Satisfaction Items . . . . . . . 56

10. Life Satisfaction Items Retained for Factor Analys is . . . . . . . . . . . . . . . . 57

11. Factor Analysis of Life Satisfaction Items . . . 58

12. Rotated Factor Matrix of Life Satisfaction Items . . . . . . . . . . . . . . . . 59

13. Life Satisfaction Items . . . . . . . . . 60

14. Factor Analysis of Reminiscence Items . . . . . 61

15. Rotated Matrix of Reminiscence Items . . . . . . 62

16. Functions of Reminiscence . . . . . . . . . 64 
CHAPTER I

Introduction and Literature Review

I have often thought what a melancholy world this would be without children, and what an inhuman world without the aged.

Samuel Taylor Coleridge

America is growing oldex. With the advancement of medical science and technology, today human beings are living longer. The U.S. Bureau of Census states that in 1984, persons 65 years or older numbered 28 million or 11.9 percent of the U.S. population. Since 1900 the percentage of Americans over 65 has tripled. The fastest growing segment of the population in the 1980 census included those individuals 85 years and older. The proportion and number of older persons will continue to grow more rapidly than any other age group. By the year 2030, 60 million Americans, representing 228 of the total population, will be over 65 (American Association of Retired Persons, 1985). Americans are not only living longer, they are also maintaining their health longer. It is not uncommon to find people in their $70 \mathrm{~s}$ and $80 \mathrm{~s}$ leading active 1 ives.

Since people are generally living longer, and older adults are beginning to represent a significant proportion of the American population, attitudes toward the elderly and the aging process are becoming more important than ever. 
Attitudes Toward Aging and the Elderly

When American culture is examined, one finds that negative attitudes toward aging and the elderly derived from two factors. First, the United states is a Western culture heavily influenced by the ancient Greek tradition, and secondly, it has structurally changed from an agricultural society to a highly industrial and business oriented society.

slater (1964) suggests that our ideas and attitudes about aging stem from the ancient Greek tradition. The classical Greek view of aging was very negative. The Greeks valued youth and stressed the misfortunes of the old. Within the classical Greek view, once a person has passed his or youthful years, it is better to die than to suffer the indignities of old age. The ancient Greeks believed that if a person dies young, that individual is honored by the gods, but one who lives into old age is being punished by the gods (Nussbaum, Thompson, \& Robinson, 1989).

One ancient myth clearly illustrates the Greeks' negative attitude toward aging. The myth tells that Eos, the Goddess of Dawn fell in love with the mortal, Tithonus, and convinced zeus to grant him immortality. Unfortunately, she forgot to ask for perpetual youth, so he grew older and older. The story concludes, "Tithonus became daily older, greyer, and more shrunken, his voice grew shrill, and when Eos tired of nursing him, she locked him in her bedroom, 
where he turned into a cicada" (Graves, 1955, p. 150).

Aristotle perceived old age as a time of hopelessness where solace could only be achieved through talking and thinking about the past. In the Rhetoric, he wrote of old people, "They live by memory rather than by hope, for what is left to them of life is but little compared to the long past. This, again, is the cause of their loquacity. They are continually talking of the past, because they enjoy remembering" (Aristotle, 1927, p. 324).

our present attitudes toward aging can also be attributed to structural changes in society. When agriculture was the dominant economic force in the United states, the old with their knowledge of farming were productive for many years, and theix wisdom was passed orally from one generation to another. During this period, published material was rare, so oral history was very valuable.

Now that America has evolved into an industrial and business oriented society, the young rapidly replace the old in the most productive roles. The new information of the young is valued more than the long honored tradition of the old. Oral history has been replaced with printed resources. society rewards the young because they are more knowledgeable on the latest technological advances. In this society of constant change, old people are like outdated technical equipment, they are replaced with faster and more 
efficient models which need less maintenance.

Empirical studies can also illuminate our understanding of attitudes toward aging in the United states. Since the pioneering work of Dinkel (1944), which first suggested a difference between the way young adults view the elderly and the way the elderly view themselves, well over one hundred empirical studies on aging attitudes have appeared. The major conclusions of this body of research suggest that attitudes toward aging are generally negative or ambivalent at best (Hickey, Hickey, \& Kavish, 1968; McTavish, 1971; Palmore, 1982; Tuckman \& Lorge, 1953, 1956; Wingard, 1982). In a review of numerous gerontological studies on attitudes and aging, Palmore (1982) concluded that people rate old age more negatively than other ages, and more negative stereotypes are associated with old age than other ages. He also indicated that many negative stereotypes are held by a majority of people, and training in gerontology can increase knowledge about aging and reduce stereotypes. However, negative attitudes are more resistant to change.

As previously stated, many negative stereotypes are associated with old age. This stage of life is often viewed as a time of decreased health, productivity, and social activity. For example, it is commonly thought that many elderly individuals are senile, or that most elderly people are institutionalized in nursing homes. In actuality, only $5 \%$ of the elderly are in nursing homes at any one time 
(Berezin, 1972; Brotman, 1974) and only $4 \%$ of the elderly suffer from severe senility (Katzmain \& Carasu, 1975). If milder forms of senility are included, Katzman and Carasu (1975) estimate that less than 158 of the people 65 years of age or older suffer from senility.

Research findings suggest that these negative attitudes and stereotypes toward aging and the elderly are formed at an early age. Teenagers, adolescents, and even children have indicated negative and stereotypical views toward the aged and growing old (Hickey, et al., 1968; Kastenbaum \& Durkee, 1964; Jantz, Seefeldt, Galper, \& Serock, 1976; Page, 1981; Seefeldt, 1983, 1984; Seefeldt, Jantz, Galper, \& Serock, 1977; Seefeldt \& Tafoya, 1981; Tuckman \& Lorge, 1956). Tuckman and Lorge (1956) studied the role concepts of high school students, and found that the students looked upon the years between 60 and 70 as a period of inactivity, lack of interest, and complete loss of adult roles. In their study of children between the ages of 3 and 11, Jantz et al. (1976) recorded few positive responses about growing old and being old. Children indicated that they will feel bad when they are old. When given a choice of being with, and doing things with older or younger people, the majority of the children preferred younger people. Children have been reported describing the elderly as poor, sick, ugly, and only able to look for glasses or be pushed in their wheelchairs (Jantz et al., 1976; Seefeldt, 1983). 
From the previous discussion, it may be concluded that negative attitudes toward aging exist in American society, yet it is important to note that these attitudes should be taken seriously because they can have detrimental effects on the quality of life for the elderly. Langer (1983) points out that, for the elderly, such attitudes result in less positive evaluations of the self, inhibited performance on tasks, and decreased perceptions of environmental control. Bennett and Eckman (1973) extended these findings in suggesting that attitudes toward the aging may also be critical for the adjustment and survival of the aged population. They claim that negative views of aging could cause premature death for some older people because they may be unwilling or unable to seek needed services. Bennett and Eckman also consider these attitudes to be in a feedback loop. In other words, if these negative views toward aging are perpetuated, today's youth will eventually find themselves rejected and neglected by a society they once helped to create.

\section{Reminiscence}

One activity that has been linked to negative attitudes toward the elderly is reminiscence. Reminiscence typically refers to thinking or talking about past experiences or events. Kaminsky (1984a) claims that since ancient times, reminiscence has been associated with old age. Psychiatrists, psychologists, counselors and social workers 
working with the elderly also had extremely negative attitudes toward reminiscence (Moody, 1984). Until the 1960s, most professionals discouraged older people from thinking or talking about the past. Reminiscing was considered a dysfunctional activity because it was linked with hopelessness, denial of death, escape from reality, loss of memory, and intellectual deterioration (Kaminsky, 1984a).

In the early 1960s, Robert Butler (1963) first published his work on the importance of "life review," which influenced many researchers in the field of gerontology, psychology, and sociology in such a way that they began to change their attitudes toward reminiscing from negative to positive. Butler (1968) argued that life review leads to candor serenity, and wisdom.

Although obsessive reminiscing is still considered to cause depression, guilt, and a inner sense of panic (Tamir, 1979), the evidence indicates that these negative effects are more likely to occur if reminiscing is done in solitude (Butler, 1968). Reminiscence as a communicative activity, which occurs in conversation with others, is viewed much more positively. As a communicative activity, reminiscing can serve many personal functions. Talking about the past has been shown to help one prepare for oncoming death (Butler, 1968; Georgemillex \& Maloney, 1984), defend one's self-esteem and beliefs (Prlefer \& Gambert, 1984; Tamir, 
1979), Eeel loved (Becker, Blumfield, \& Gordon, 1984), gain self-awareness and self-understanding (Kiernat, 1983; Tamir, 1979), adapt to stress (Priefer \& Gambert, 1984) and enhance one's life satisfaction (Haight \& Baur, 1984).

In addition to providing some important benefits for individuals, reminiscence can also provide significant social functions. Lesser, Lazarus, Frankel, and Harasy (1981) discovered that reminiscing can lead to the establishment of group cohesiveness. Reminiscence in intergenerational activities can also lead to positive educational results. Reminiscence can provide a historical contribution (Becker et al., 1984), and facilitate the handing down of culture (Kaminsky, 1984b). For example, Pershbacher (1984) found that encouraging the elderly to reminisce in an educational setting with children leads to more community understanding.

New research has suggested that, as a communicative activity, reminiscence can have both informative and evaluative functions for the elderly and society. Although it is important to recognize the usefulness of talk about the past, the possible significance of the elderly's ability to talk about the present and future should also be addressed. Unfortunately, little research has focused on the elderly's talk about the present and future.

In the section that follows, two major theoretical approaches to aging will be used to explore the possible 
implications of past, present, and future talk.

\section{Theoretical Approaches to Aging}

Over the last few decades, attempts have been made to explain theoretically not only the social behavior of elderly individuals, but the association of this behavior with the ability to adapt successfully to the final stages of life. Two theories that have been used to explain aging are Disengagement Theory (e.g., Cumming, Dean, Newe11, \& McCaffrey, 1960; Cumming \& Henry, 1961) and Activity Theory (e.g., Gubrium, 1973). Other theories have been proposed, but these two theories can be used to discuss the notions of time and communication.

Disengagement Theory was the first explicitly stated social-psychological theory of aging to appear in social gerontology literature. Proponents of this theory claim that successful aging depends on mutual witharawal by the elderly and society. In this perspective, the elderly learn to accept or even desire withdrawal from society. In other words, successful aging is achieved by the elderly interacting less with the community and others. Havighurst, Neugarten, and Tobin (1968) clearly described this view, - the individual's withdrawal has intrinsic, or developmental qualities as well as responsive ones; that social withdrawal is accompanied by, or preceded by, increased preoccupation with the self and decreased emotional investment in persons and objects in the environment . . . disengagement is a natural rather than imposed process. The older person with a sense of psychological well-being will usually be the person who has reached a new equilibrium 
characterized by a greater psychological distance, altered types of relationships, and decreased social interaction with persons around him. (p. 161)

The older person is depicted as someone near death who only depends on society and others for personal health needs. This outlook on aging perpetuates the negative attitudes and stereotypes which were discussed earlier. For instance, Cumming (1963) uses disengagement theory as an argument to explain why elderly people are not used in functional roles. She states that "the organization of modern society requires that such competition for powerful roles be based on achievement. Such competition favors the younger because their knowledge is newer . . " (Cumming, 1963, pp. 384-385).

Another aging theory, which is contradictory to Disengagement Theory, is Activity Theory. Activity Theory has never been formally named as such. Rather, it is a label attached to a collection of research findings on activities and morale in old age. Although the activity concept has not been clearly defined, it has been assumed that researchers consider activity to mean involvement in social interaction. Research in this area suggests that there is a causal relationship between high levels of activity and high morale (Burgess, 1954; Lebo, 1953; Reichard, Livson, \& Peterson, 1962). Proponents of this perspective also claim that a positive relationship exists between life satisfaction and high levels of social 
interaction (Adams, 1969; Bley, Goodman, Dye, \& Haiel, 1972; Cutler, 1973; Larson, 1978; Lemon, Bengston, \& Peterson, 1972; Nussbaum, 1983a, 1983b; Tobin \& Neugarten, 1961). Activity Theory, therefore, implies that successful aging is contingent upon the older person's ability to maintain an active social life. Except for biological and health changes, older people are considered the same as middle-aged people. This view assumes that the elderly want to engage in social activities beyond retirement, and it is society, not the elderly, that limits the choice of activities. Havighurst, Neugarten, and Tobin (1968) assert that the elder who ages optimally is the person who "maintains the activities of middle age as long as possible and then finds substitutes for those activities he is forced to relinquish...." (p. 161). For example, if an older person is forced to retire, he or she should continue to remain active by participating in clubs, travelling, taking up hobbies and/or working as a volunteer for various organizations.

Disengagement Theory and Activity Theory can both be used to explore the significance of talking about the past, present, and future. In examining these three types of talk from the disengagement perspective, one can assume that talk about the past is exclusively relevant to the aging process. Disengagement theorists argue that successful aging is obtained by the elderly's ability to withdraw from society. 
Once disengaged from the career or life patterns maintained for many years, elderly people's present life is suddenly transformed into the past history. Without support and suggestions for their reengagement in the society, the elderly are left only with the past. In other words, Disengagement Theory implies that the elderly person does not have the future to talk about, because in order to talk about the present and future, he or she would still need to be involved in the present society. However, if the elderly could only focus on the past, he or she would remain withdrawn from current events. From this perspective, thinking about the past may also play an important role in the disengagement process in that it helps the elderly to withdraw from society without interacting with other people. Contrary to the Disengagement Theory, the Activity Theory suggests that talk about the present and future, as well as the past, is important. Proponents of Activity Theory consider life satisfaction to be related to high amounts of social interaction; therefore, any talk that is used to avoid psychosocial deterioration would likely be regarded as Eunctional. From this perspective, talk about the present and future allows the elderly person to remain involved in the society. Talk about the present and future is conducive to engagement or reengagement in more social encounters. It is quite logical to assume that people are more likely to converse with an elderly person if the 
conversation is not simply a monologue of past experiences. In accordance with the Activity Theory, talking about the past is functional, if it is used to make sense or give meaning to the present and future. In other words, the elderly person's experiences remain valid, if they are used to contribute needed information to a present or future situation.

For the most part, this study focused on elderly people that were actively involved in various community organizations. Some of these organizations included an intergenerational day care center, the American Association of Retired People, a kitchen band, and a recreational vehicle club. Since most of the people in the sample were active, it was not possible in this study to make direct comparisons between the efficacy of Activity Theory and Disengagement Theory. Rather, the focus of the current study was to explore initially the impact of communication related to three chronological periods on life satisfaction, perceived contribution, and functions of reminiscence, which might offer, indirectly, views about the Disengagement Theory and Activity Theory. It was assumed that an association between present and future talk and 1 ife satisfaction and perceived contribution would constitute support for Activity Theory and, conversely, that an association between past talk and life satisfaction and perceived contribution would constitute support for 
Disengagement Theory.

From the previous discussions in the chapter's sections, it may be concluded that there is a problem with how the American's view the aging process. The research reviewed indicated that most people, including children, have negative or at least ambivalent attitudes toward aging and the elderly. Although these negative attitudes have been linked to unsuccessful aging, little research has focused on how we can change these negative attitudes socially. One solution to this national problem is a program involving intergenerational contact. In addition to eliminating and transforming attitudes toward the elderly at an early age, these intergenerational programs could also provide the elderly with more opportunities to talk about the past, present, and future. Their talk of the past could be used to educate younger people. Their new experiences in the program would allow them to talk about ongoing events.

\section{Intergenerational Programs}

Literature on attitude formation indicates that our attitudes developed during early childhood remain relatively stable (Klausmeier, 1974). Children's attitudes toward aging and the elderly in the early childhood, therefore, is an important area of study. As mentioned previously, studies report that children have negative attitudes toward aging and the elderly. One possible reason for these negative attitudes is that children frequently grow up with 
Iimited exposure to older people, which perpetuates the myths and fears about aging. Many children live far from their grandparents and do not have many opportunities to interact with older people because the elderly are often segregated from the young. Nussbaum (1981) and Nuessel (1982) point out that our society segregates the elderly into urban ghettos, so-called retirement communities, and into nursing homes, which separate the old from the main stream of daily activity. This segregation may have detrimental effects for both the old and the young. The elderly could lose the meaning of their past experiences and their stake in the future. The children could be deprived of learning about these past experiences. Seefeldt (1984) cautions that "with little contact between the young and old, there is little or no possibility of children learning to care for, be concerned for, or cooperate with the older generation" (p. 320).

To counteract this trend toward the separation of the generations, a variety of intergenerational programs have been developed nationwide to provide for frequent and meaningful contact between the young and the old. These programs integrate elderly people in school and community programs, such as day care centers, foster grandparent programs, and tutoring programs (Struntz \& Reville, 1985). These intergenerational programs are based on the assumption that both the young and old will benefit from these 
interactions. These programs are expected to improve the elderly's life satisfaction and feelings of self-esteem and self-worth. It is also assumed that if children share experiences with older people in either a school or nonschool setting, they will advance their learning skills, and begin to develop more positive attitudes toward aging and older people.

Given the assumption that intergenerational programs will produce positive relations between the old and the young, research has provided inconsistent findings. Some studies have concluded that intergenerational contact leads to positive effects. The senior citizen school Volunteer Program (SCSVP), one of the programs of Generations Together based at the University of Pittsburgh, report that their program has made a significant positive impact on the teachers, senior citizens, and children (Newman, 1985). One of their findings, based on 99 teachers' logs and questionnaires, suggests that the senior volunteers contributed to students' academic and social growth. Other positive findings were found in the summary of questionnaires answered by 65 of the senior citizen volunteers. Ninety-seven percent of the volunteers felt that the program had improved their feelings of self-worth, $20 \%$ reported improved health that seemed to be related to their participation in the program, and 258 stated that the program gave them the opportunity to learn new skills. 
Almost all of the volunteers reported that the experience was a productive and rewarding use of their free time. In a SCSVP 1979-80 study of 256 fourth, fifth, and sixth grade children, which included both participants and nonparticipants in the intergenerational program, the results indicated that the children who interacted with the elderly volunteers had more positive attitudes toward the elderly than the children without such contact (Newman, 19851 .

Kramer and Bumgarner (1985) also report positive findings in their study of an intergenerational day care center. They found that the program had a positive impact on the younger employees, the elderly, and the 4 and 5 year old children. They claim that the elderly became more actively involved in their communities, demonstrated more confidence and assertiveness, and seemed more giving and patient in their relationships with others. Two studies (Seefeldt, Jantz, Serock, Galper, 1977; Trent \& Glass, 1985) which examined the impact of an intergenerational curriculum, also found that children and adolescent's attitudes toward the elderly became more positive following an intervention that included spending a great amount of time with active elderly people.

Other studies report that intergenerational contacts are ineffective in enhancing the elderly's life satisfaction and developing children's positive attitudes toward the 
elderly. Newman, Baum, and Vasudez (1983) discovered no increase in 1 ife satisfaction as a result of volunteering in the intergenerational school programs. They suggest that the elderly that volunteer for such programs may already enjoy a high degree of life satisfaction.

Chappell (1977) found no differences in attitudes between fifth and sixth grade children who had maximum contact with elders and those who had limited contact. One other study (Lyons, Newman, \& Vasudez, 1985) which examined that impact of intergenerational curriculum on children in grades 1 to 6 , also found no differences between control groups and experimental groups.' Both groups were revealed to have positive attitudes toward aging and older adults. One study (Immorlica, 1980) even reported elementary children increasing their negative attitudes toward elderly as a result of the intergenerational contact.

Although intergenerational research studies have resulted in contradictory findings, the general assumption remains that intergenerational contact is important for the young and the old. If we are to claim that intergenerational communication will improve children's perceptions of the old and the elderly's perceptions of themselves, further research is needed to explain these contradictory results. The current study examines young children in an intergenerational day care center to provide some possible reasons for the inconsistent findings 
regarding attitudes toward the elderly.

This research was designed to examine empirically attitudes toward aging and the elderly from the perspective of the old and the very young. Four lines of literature were reviewed. Given this chapter's discussion on attitudes toward the elderly, the significance of the elderly's past, present, and future talk in relation to life satisfaction, perceived contribution, and functions of reminiscence in conjunction with the two theories on aging, and the proposed activity of intergenerational contact, the overall guiding research questions are proposed as follows:

RQ1: Do children in an intergenerational day care center have different attitudes toward aging and elderly people from children in conventional day care centers?

RQ2: How are talking about past, present, and future related to the elderly's life satisfaction, perceived contribution, and functions of reminiscence?

The research design and methods used to explore these two guestions are presented in the following chapter. 


\section{CHAPTER I I}

\section{Methods}

Two studies were conducted to address the research questions. This chapter describes the methods used in both of the studies, respectively. The first study used face-toface interviews to provide an answer to the first research question, which explored children's attitudes toward aging and elderly people. The second study, in terms self-report questionnaires, explored elderly people's talk about the past, present, and future in relation to life satisfaction, perceived contribution, and functions of reminiscence. subjects, methods, and procedures of these studies were approved by the Human subjects Review Board at the university.

\section{study I}

supjects

To explore the attitudes that children have toward aging and the elderly, 43 children were interviewed. The mean age was $4.11,23.3 \%$ yere male and $76.7 \%$ were female. The children were drawn from one intergenerational day care and three conventional day care centers located in Northern California. The sample size and gender composition were equivalent to insure validity of comparison. The intergenerational day center sample consisted of 21 children between the ages of 3 and 6 (mean age was 4.3 ), 23.8\% were male and were 76.28 female. The conventional day care 
center sample consisted of 22 children between the ages of 2 and 7 (mean age was 3.9), 22.78 male and 77.38 female. The selection of the children to participate in the study was conditioned on parent's or guardian's consent. The children of the intergenerational day care center were from low income families, while the children of the three other day care centers were from low to midale income families. Measurements

Children's Attitudes Toward Elderly Questionnaire. The Children's Attitudes Toward Elderly (CATE) instrument was developed in 1976 by the Department of Early Education and the Center on Aging at the University of Maryland. The instrument was designed to assess children's attitudes toward old people through analysis of the affective, behavioral and cognitive components of attitudes (Jantz, et al., 1976). The instrument was created specifically for children between 3 to 11 years of age. The entire CATE consists of four subtests: Ford Association, Semantic Differential, and Picture Series, which measure children's attitudes toward elderly. The fourth subtest, concept of Age, is a instrument based on Piaget's theory, which measures children's understanding of age. since the pilot study conducted in 1976, the CATE subtests have been used in several studies addressing children's attitudes toward elderly (e.g. Kramer \& Bumgarner, 1985; Lyons et al., 1985; Seefeldt, 1983, 1984; seefeldt \& Jantz, 1977; seefeldt et 
al., 1977). Only the Picture series and the Word Association subtests were used for the present study, which are described in the following discussion, respectively (see Appendix A).

Since young children have difficulty in understanding abstract verbal concepts, the Picture series subtest was developed to allow them to respond to concrete visual representations of age differences. Eight questions comprised of open-ended and closed-ended questions were used to elicit the children's responses towards the pictures. The pilot testing of the Picture series subtest by Jantz et al. indicated a high degree of validity and reliability. of their random sample, 180 children, between ages 3 to 11 , were able to understand the concepts depicted in the pictures, and able to answer the picture questions with a high degree of consistency of category choice. Their coefficients in interrater reliability ( 2 raters) on category scoring for the subtest ranged from .7184 to .9777 .

The Word Association subtest of the CATE contains five open-ended questions which address the cognitive, affective, and behavioral components of children's attitudes toward elderly. The cognitive component is measured by the following three questions: 1) "What can you tell me about old people?" 2) "What old people do you know?" 3) "Can you give me another name for old people?" The question, "How do you feel about getting old?" is used to elicit responses 
related to the affective component. The follow-up question, "What do you do with that person?" refers to the older people the child knows and the behavioral component of the children's attitudes.

The pilot study of the Ford Association subtest also indicated a high degree of validity and reliability. The administration of the instrument to a random sample of 108 children, between ages 3 to 11 , indicated that the children consistently understood and responded to the test items. The coefficients of inter-rater reliability (2 raters) on category scoring for the subtest ranged from .7977 to .9838 .

Revised CATE. Since both validity and reliability on Jantz et al. (1976) on the Picture series subtest and the Word Association subtest appeared to be high, their prescribed categories were used to analyze the data in the present study (see Appendix A).

Revisions were made on both of the CATE subtests in the present study (see Appendix B). First, a revision was made on the selection of pictures to be used for this test. The original version of the picture series used four 8" $\times 10^{\prime \prime}$ drawings of men at four stages of life. The available photo copies of these drawings were not clear and also tended to elicit negative physical descriptions towards the elderly man. Therefore, two new photographs were developed for this test. The caretakers of the four day care centers were primarlly female; therefore, two Eull face photographs of 
females were used (see Appendix C). The two $4 \times 6$ photographs consisted of a 69 year old mother and her 37 year old daughter. A mother and daughter were used because of their similar features. The women wore earrings, but were requested not to wear make-up. Each of the women was photographed in similar poses with similar facial expressions, so that the subject's responses would be based on the single variable of age.

The five word association questions, as well as two additional questions were used for the revised questionnaire designed for the present study. The follow-up question, "How often do you see this person?" was added to determine if the amount of contact with the older person was a contributing factor to the child's attitude. The other additional follow-up question, "Do you like being with this person?" was asked to find out if the child considered the time together as a positive or negative experience.

\section{Pretest}

Both the Picture Series subtest and Ford Association subtest adapted from the CATE were pretested on children on site at the intergenerational day care center. Five children ( 3 males, 2 females) between the ages of four and six were pretested on the Ford Association subtest, and one four year old female was pretested on the picture series subtest. Each child was informed by the teacher that the researcher needed to ask them some questions to help her 
with her school homework. This instruction by the teacher allowed the child to feel more at ease about the interview. After some rapport was established with the child, the researcher asked each question on a one-to-one basis. Each interview was audio taped to record the exact wording of the children's responses.

No problems were found on the Picture series pretest. Therefore, no Eurther revision was required. However, results from the Word Association pretest made it necessary to revise some of the items. The first revision was made on the ordering of the word association questions. The first question, "What can you tell me about old people?" was moved to the seventh position. The pretest indicated that this question was too abstract to be asked first. The children in the picture test had less difficulty providing concrete examples. Therefore, the revised questionnaire began with a question that called for a concrete example. The question "What old people do you know?" was used for the first question. An addition was also made to the first question. If no response was made on the first question, a follow-up question, "Do you have a grandma and/or grandpa?" was asked. The follow-up question provided the opportunity to ask four of the succeeding questions. Without the opportunity to ask these questions, the instrument would not have drawn enough data for analysis.

The results of the pretest also indicated that audio- 
tape was not the best means for recording the children's responses. Parts of the interviews were inaudible because the children frequently spoke too softly, and/or put their hands in or near their mouths while answering the questions. The chlldren also responded to some of the questions nonverbaliy. In order to improve the quality of the recorded interviews, video taping was used for the final data collection.

\section{Procedures}

Directors from the four day care centers were contacted by phone and in person by the researcher to obtain permission to use their center for the study. The day care directors distributed the consent forms to the parents/guardians of the children. The children from the intergenerational day care center and the three conventional day care centers were interviewed on-site by the researcher. Except in the case of one conventional day care center, the researcher visited each day care center at least once, prior to the scheduled interview day, as an attempt to establish rapport with the children. The researcher established rapport by engaging in various preschool activities. Each child who participated in the study was told by his or her teacher that the researcher needed some help on her homework. This instruction was given so that the child would not think that the task was a test. To avoid interruptions from the other children, the video taped 
interviews were conducted in an office or classroom separate from the other day care activities. The following instructions were given by the researcher before the children responded to the revised CATE interview questions: "Hi, my name is susan and I need some help with my homework. I'm going to ask you some questions. It will only take a few minutes, and then you can go back and play." The researcher next asked the child his or her age, and proceeded with the revised questions from the Picture series and Ford Association subtests of the CATE questionnaire. Each interview was video taped to preserve both the verbal and nonverbal responses of the children. Each child was allowed sufficient time to respond, but generally 30 seconds without a response led to the reading of the next question. Although questions were repeated when necessary, the children responded voluntarily without being prompted. Each interview took about 20 minutes to complete.

\section{Study II}

\section{subjects}

To study the life satisfaction of elderly and their talk about the past, present, and future, 66 older adults volunteered from six different contexts. The sample consisted primarily of retired persons (86.48 retired, 19.48 working). The discrepancy in the employment figures was due to the fact that some subjects were retired, yet continued some form of employment. Volunteers were obtained from an 
recreational vehicle club $(\underline{\underline{n}}=17)$, a kitchen band $(\underline{n}=7)$, a convalescent home $(\underline{n}=5)$, a miscellaneous group of grandparent's older friends $(\underline{n}=5)$, a chapter meeting of the American Association Retired Persons ( $\underline{n}=24)$, and an intergenerational day care center $(\underline{n}=8)$. All subjects were between the ages of 50 and 86 (mean age was 71.14), 35.48 male, $64.6 \%$ female. The ethnic backgrounds of the respondents were $4.5 \%$ Hispanic, $93.9 \%$ White, and $1.5 \%$ Filipino. Except for the intergenerational day care center, which was located in an urban community of Northern California, the remainder of the sample was from a moderately sized rural community of Central california. The subjects 1 ived in houses $(80 \%)$, apartments $(1.5 \%)$, retirement villages (1.5\%), convalescent homes $(6.2 \%)$, and other type of residence $(10.88)$. Only 19.78 were working at the time of the study.

Measurements

Demographic items. Two instruments were revised to be used for the elderly subjects (see Appendix D). Part I of the elderly questionnaire was composed of demographic questions. The respondents were asked to provide information regarding their sex, age, living arrangements, ethnic background, professional background, and involvement in organizations. The questions pertaining to professional and organizational background were especially important in assessing their level of activity. 
Life satisfaction. Part II of the questionnaire was developed from Neugarten, Havighurst, and Tobin's (1961) 20item Life satisfaction Index (LSIA). A questionnaire containing 31 seven-point likert items was constructed from the original LSIA. Two questions were deleted from the original LSIA. "Compared to other people my age, I've made a lot of foolish decisions in my life" was deleted because of a procedural error. "In spite of what people say, the lot of the average man is getting worse, not better" was not included because of vague terminology. The phrase "down in the dumps" was replace with "depressed" on one item so that it would sound more intelligible. "I have made plans for things I'll be doing a month or year from now" was developed into two separate items since the terms month and year are too diverse. The word "somewhat" was deleted for "I feel old and somewhat tired" because somewhat was one of the points on the scale.

Perceived contribution. Items $24,26-30$ were added to the Part II of the questionnaire. These six items were generated from statements written by 44 students in three public speaking classes at a community college. students were asked to write a series of statements concerning the life satisfaction of older people. Six items were selected from the one hundred and seventy-one statements written. These items were selected because they referred specifically to the functional role played by the elderly in society, 
which was an area that did not receive adequate attention in the original questionnaire. This functional role is identified in this study as "perceived contribution." Communication about the past, present, and future. Items $2,6,10,21,25$, and 31 were added to Part II of the questionnaire to discover if the subjects talked about the past, present and future. Both negative and positive items were used to test for reliability.

Functions of reminiscence. Part III of the elderly guestionnaire was generated from Havighurst and Glasser's (1972) 48-item Questionnaire on Reminiscence. A 28-item questionnaire was constructed using five-point Likert scales. The most significant difference between the original and revised questionnaire was the distinction between dyadic and monadic reminiscing. In the original questionnaire the term "reminiscing" was used to represent both silent and oral recollection of the past. In the revised questionnaire 13 items from the original instrument were rewritten to distinguish dyadic reminiscing from monadic reminiscing. For example, the statement "Reminiscing gives me a good feeling" was changed to say "Talking about the past gives me a good feeling," and "Thinking about the past gives me a good feeling." The item, "Bringing up the past gives me something to talk about" was not given a monadic counterpart because the specific function of reminiscing on this item was to promote 
dialogue. Another item written in the dyadic form only was "I have someone to talk with about the past." This statement did not need a monadic counterpart because it measured the availability of a partner.

Pretest

The elderly questionnaire was pretested on one 73 year old man and one 69 year old woman. Both subjects were white. The pretest was conducted to discover any semantic problems. Both subjects reported that they fully understood the questions and had no difficulties in responding to the questionnaire.

\section{Procedures}

The volunteers obtained from the recreational vehicle club, the kitchen band, the miscellaneous group, and the chapter of the American Association of Retired Persons were all contacted in person by the researcher's grandparents at group meetings. Since the researcher's grandparents were members of these organizations, they distributed the written questionnaires. Those members who agreed to participate were instructed to read the directions attached to the questionnaire (see Appendix D). Once the questionnaires were completed, the volunteers returned them to the researcher's grandparents so they could be delivered to the researcher.

The volunteers from the convalescent hospital were obtained through the social director of the hospital. She 
distributed and collected the written questionnaires from the residents, and returned them to the researcher.

The volunteers from the intergenerational day care center were obtained through the director of the center. The researcher gave the director the copies of the written questionnaires so they could be distributed at their monthly meeting. The completed questionnaires were then mailed back to the researcher. 


\section{CHAPTER I I I}

Data Analysis

Study I

\section{CATE coding}

The original care coding scheme used categories that related to the affective, behavioral, and cognitive components of attitudes. Surprisingly, after a review of the responses of the children in the present study, it was discovered that the majority of the children's answers did not correspond to the categories defined in the CATE scoring instructions. For each of the questions in the picture Series subtest and the Word Association subtest, there were either two or three categories in which the responses could be appropriately coded. The authors of this instrument assumed that the children would be able to respond to each question with an answer that depicted an understanding of aging. For example, depending on the question, the response would be categorized as either evaluative or physicaldescriptive; affective, physical, or behavioral; withactive, with-passive, for (doing something for the other person); or positive, negative, or neutral. A review of the children's responses given in the present study made it apparent that their interpretations of the questions were quite different from those that might be provided from an adult perspective. The majority of the children were unable to provide answers to illustrate that they had an 
understanding of aging as an abstract concept. The children sometimes bypassed the question, repeated the question as an answer, or gave an irrelevant response. These types of responses occurred for both abstract and concrete questions on aging. Had the prescribed categories been employed, much of the data would have been disregarded. A new coding scheme, therefore, was developed post hoc to explore different levels of thinking in answering the questions (see Append ix E) .

A pertinent theoretical framework to understand this new coding scheme is the Vygotskian perspective. In his book Thinking and speech (1987), Vygotsky proposed a rival theory to Piaget's theory on children's cognitive development. Vygotsky felt that it was crucial to examine the dynamic relationship between thinking and speech, which undergoes qualitative changes from early childhood to elementary ages, and to adolescent period.

Vygotsky proposed that there are three developmental stages of thinking. The first level of thinking is syncretic. At this level a child uses a word to represent a meaning that often coincides with those of adults, but the child does not know at this stage that the meaning intersects with the word. The child's thoughts at this stage are irrational and subjective. His or her thinking is guided by emotion.

The next level of thinking is complexive. At this 
stage a child uses words to represent concrete objects, but the child does not know the conceptual meaning behind the word. The child can understand concrete objects as opposed to abstract thought. The most common form of complexive thinking, which is prevalent among preschoolers, is the pseudoconcept. The pseudoconcept is used to describe incidents where the child first appears to understand a concept because he or she uses an adult word to represent an object. However, the child does not understand the entire meaning the word represents. The child only understands that the word is associated with a particular object.

The highest level of thinking is conceptual thinking. At this final stage, which occurs during adolescence, the child truly understands concepts rationally and logically. The child is able to recognize relationships and differences between objects.

Vygotsky believed that children's speech developed from social speech, to egocentric speech, and finally to internalized speech. This idea is quite contrary to Piaget, who postulated that children's speech developed from inner speech, to egocentric speech, and then to social speech.

The new coding scheme also explained the children's responses in terms of different levels of cognitive development. For example, the highest level or most appropriate answer would be one that belonged to the original CATE categories. To further investigate those 
responses that were deemed most appropriate, more specific categories were also developed. The lowest level of response belonged to the categories named "Don't know," "Irrelevant subject," "Irrelevant Information," and "Repeat Question."

For each question, two coders examined the 43 responses to discover common answers. The responses determined to be similar in appearance were given a label that best characterized these answers.

Picture Questions. The first descriptive picture question asked, "Why do you think the person you chose is the oldest?" six categories emerged in response to this question. The first category was called "Don't know" because it referred to all responses in which the child was unable to provide an answer. Responses such as "I don't know," "Because," and "I forgot" were considered to fit under the "Don't know" category.

The next two categories were developed to categorize irrelevant answers. One irrelevant category was named "Irrelevant subject," because the child's response did not relate to the question being asked. For example, "I'm going to the park today" would be an "Irrelevant subject" response, since the response does not address the question. The other irrelevant category was named "Irrelevant Information" for the child would attempt to answer the specific question, but the response did not provide the type 
of information which would normally be associated with the question. Some "Irrelevant Information" responses given, for why the person chosen was the oldest, were "She has a haircut," "She's new," and "She's laughing." The fourth category was named "Repeat Question," since the child used the rephrased question as an answer without providing any further explanation for his or her cholce. Responses stating "She looks the oldest," "Because she looks old," or "Cause she looks older than her" were considered "Repeat Questions."

The fifth category was called "Subjective Self" because the child's response indicated a personal preference or a sense of confidence in his or her selection. Examples from this category were "Because I choose her," "Because I like her," and "Because I know everything." Responses which belonged to this category were more appropriate than the previous questions because the child was able to answer the question with a relevant response, yet this category was not the most appropriate type of answer because it was more egocentric than logical.

The sixth category was named "Affective," for it included responses pertaining to feelings or emotions. One example which fit this category was "Because I like her." This type of answer was very high on levels of cognitive development. The responses wich belonged to this category referred to a specific reason. This category was not deemed 
the most appropriate answer since it was based on emotion rather than $\operatorname{logic}$.

The seventh category was called the "Why Answer" because the child was able to explain correctly the reason behind his or her selection. This type of response was considered to be the closest attempt at a higher level of thinking. Responses such as "She has wrinkles," or "She's a grandma" were deemed as "Why Answers" because the child explained his or her reason on the basis of physical description or social role.

The last category was simply labeled "Missing." Procedural exrors made by the researcher and/or the respondents belonged to this category.

The second picture question asked, "How will you feel when you are that old (referring to the older woman)?" Twelve categories were used to group the similar responses to this question. Five of the categories used for the previous question were employed for this question. They were "Don't know," "Irrelevant subject," "Irrelevant Information," "Repeat Question," and "Missing." Six new categories were named to identify highly appropriate answers. Four of these categories were added to identify specific activities, and two of these categories referred to adjectives.

One activity category was named "Domestic/work Related Activity" because it included responses which described 
household chores or work that the child would do when he or she was older. For some of the subsequent questions it referred to chores that the child and older person could do together. "Domestic/Work Related" activities included cleaning, washing, cooking, vacuuming, working, and carrying groceries.

The second activity category was called "school Orlented Activity" since it referred to responses that described learning activities the child partook in at school. Examples of this type of activity included studying homework, drawing, and cutting.

The third activity category was named "Caretaking Activity" because it was used to group the responses in which the child felt he or she would need someone to take care of him or her during old age. In relation to some of the other succeeding questions this category included responses that described how the child or the older person was going to help the other with a personal activity. "Caretaking" activities included "show her how to walk," "Give me some food," and "Make me feel better."

The fourth activity category was called "play Activity." This category included any responses in which the child stated "play," or described a specific playful activity, such as a game or telling jokes.

The two adjective categories were named "Negative Adjective" and "Positive Adjective." Examples of "Negative 
Adjectives" included "sad," "sick," "and bad." Examples of "Positive Adjectives" included "fine," "good," and "happy."

A Einal category was added to group responses in which the child interpreted "old" from a child's perspective instead of an adult's perspective. This category was called "Quasi-Scientific Understanding." Examples from this category included responses where the child interpreted old to mean a numerical age older than his or her age, older children, and bigger or taller. For some of the succeeding questions it also included a specific activity or action associated with adulthood, such as smoking, driving, and getting married or divorced. This category was not as appropriate as the preceding activity and adjective categories, but it was considered to be better than the lowest level categories.

The same categories were used for the third picture question, "What things could you help this person do (referring to the older woman)?" and the fourth picture question, "What things could she help you do?" Fourteen categories were used to group responses to these questions. Eleven of these categories were defined in the discussion of categories used for previous questions. These categories were "Don't Know," "Irrelevant subject," "Irrelevant Information," "Repeat Question," "Affective," "Domestic/Work Related Activity," "School Oriented Activity," "Caretaking Activity," "Play Activity," "Quasi-scientific 
Understanding," and "Missing." The three new categories added were "Social Activity," "Role Related," and "violent Answer." All of these categories required a higher level of thinking, and were thought to be on the same level as the previous activity categories.

The "Social Activity" category was added to account for responses which described the child and the older person participating in activities of a social nature. Some examples of "Social Activity" included visiting each other, going to church or restaurants, watching television, and taking the dog for a walk.

The "Role Related" category was added to refer to responses which assigned a specific role to either the child or the older person. Examples of roles included grandma, friend, and teacher.

The "Violent Answer" category was added because one response indicated inflicting bodily harm. The violent response was "beat up."

The fifth question on the subtest asked the child to guess the age of each of the women. The children who were able to provide more than "Don't know," responded with a numerical answer, a descriptive answer, or with a combination of both. The numerical replies were first examined by rank. The ranking of the women was considered correct if the child gave the older woman the greater number of years. The numerical replies were then evaluated by 
range. In order to establish an acceptable age range, twenty-nine community college students enrolled in speech communication classes were shown each of the women's pictures and asked to write down the age of each woman on a piece of paper. The age range for the younger woman was between thirty and forty-nine. The age range for the older woman was between fifty-six and eighty-five. These ranges were then used to evaluate the children's answers. The descriptive responses to the age question were also evaluated in two ways. First, the answers were judged in terms of whether or not the child was able to discriminate concerning the ages of the two women. For example, if a child said that the older woman was "old, old," and the younger woman was "a little bit old," this response was considered to be a correct discrimination. However, if the child said the older woman was "very old," and said "I don't know" for the younger woman, this response was considered to be a nondiscrimination. The descriptive responses were also evaluated. The responses for each woman were deemed correct only if the child described the older woman as being older and the younger woman as being younger than the older woman. Children who were correct in both range and discrimination were identified as having the most appropriate answers, and having the best understanding of age.

The sixth descriptive question on the picture Series subtest asked, "Why do you prefer to be with the person you 
indicated?" Sixteen categories were used to group responses to this question. Except for the deletion of two categories which did not apply to the question, ("Quasi-scientific Understanding" and "Violent Answer"), all of the same categories used for the third and fourth descriptive questions were employed for the sixth question. Three additional categories were also included. "Discipline" was added to refer to responses in which the child mentioned an older person performing disciplinary actions, such as spanking or yelling. "Physical Artifact" was added to account for the responses where the child's preference was based upon a physical attribute that did not relate to age. Examples Erom this category included jewelry, clothes, and the color of eyes. "Age Related" was added to address the responses in which the child's preference was based on whether the person was old or young. Responses which belonged to these three categories were considered high in terms of their appropriateness.

The seventh descriptive question on the Picture series subtest asked, "What kinds of things could you do with that person (referring to the person the child chose in the previous question)." The same categories used for the third and fourth descriptive questions were used to categorize responses to this question.

Hord Association Questions. The first descriptive question on the Ford Association subtest asked, "What old 
people do you know?" Six categories were used to identify the responses that airectly answered the question. The categories consisted of "Grandparents and Great Grandparents," "Other Relatives," "older Children (including siblings)," "Teachers," "Specific Names Without Reference to Relation," and "Acquaintances (neighbor, older people at the park)." The responses to the prompted question, "Do you have a grandma and grandpa?" were labeled with the "Grandparents and Great Grandparents" category. These categories were not judged in terms of their appropriateness. The responses given did provide information on whether or not the children thought their teachers were old.

The second descriptive question on the word Association subtest asked, "What do you like to do with that person (referring to the previous answer)?" Fifteen categories were used to group the responses. Fourteen of the categories were derived from the picture subtest categories. These categories included "Don't know," "Irrelevant Subject," "Irreievant Information," "Repeat Question," "Affective," "Domestic/Work Related Activity," "School Oriented Activity," "Caretaking Activity," "Play Activity," "Social Activity," "Role Related," "Negative Adjective," "Positive Adjective," and "Missing." . The additional category was named "Exercise." This category referred to responses that indicated physical exercise other than play. 
Some examples of "Exercise" were running, skipping, and working out. This new category was considered to be just as appropriate as the previous activity categories.

The third descriptive question on the Word Association subtest asked, "Can you give me another name for old people?" Responses to this question were identified with the same categories used for the first descriptive word association question, as well as "Don't Know," "Irrelevant Subject," "Quasi-Scientific Understanding," and "Missing."

The fourth descriptive question on the Ford Association subtest asked, "How do you feel about getting old?" This question used the same categories identified for the picture question, "How will you feel when you are that old?" In addition to these categories, "Exercise" and "Social Activity" were included.

The last two descriptive questions on the Word Association subtest asked, "What can you tell me about old people?" and "What can you tell me about (the answer given in the first descriptive question on the Word Association subtest)?" Except for the additions of "Discipline" and "Quasi-Scientific Understanding," this guestion used the same categories assigned for the picture question, "What do you like to do with that person?"

Inter-coder reliability. Two coders were trained to assign the children's responses to the proper categories for both subtests. Reliability for the two coders' category 
scoring and the researcher's category scoring were then analyzed. The reliability analysis was performed on each question to determine the coefficients of inter-coder reliability on the category scoring. The variables for each question were defined in Table 1. The coefficients of inter-coder reliability ranged from .4235 to .9989 (see Table 2). Although the inter-coder reliability was low on a few question categories, most of the categories were highly reliable. When disagreements in coding were discovered, discussions were conducted to achieve consensus.

Table 1 Definitions of Variables for Picture Questions and Ford Association Questions

Variable Questions

Labels

Q1D

Q2D

Q3D

Q4D

GUES

DISCRIM

GRANG

ARANG

Q6D

Why do think the person you chose is the oldest?

How will you feel when you are that old? What things would you help this person do? What things could she help you do? Refers to type of guess given on women's ages Refers to ability to discriminate between the older and younger woman Refers to the range of the grandmother's age Refers to the range of the aunt's age Why do you prefer to be with the person you chose?

Q7D

what kinds of things could you do with that person? 
Table 1

Definitions of Variables picture Questions and Ford Association Questions (continued)

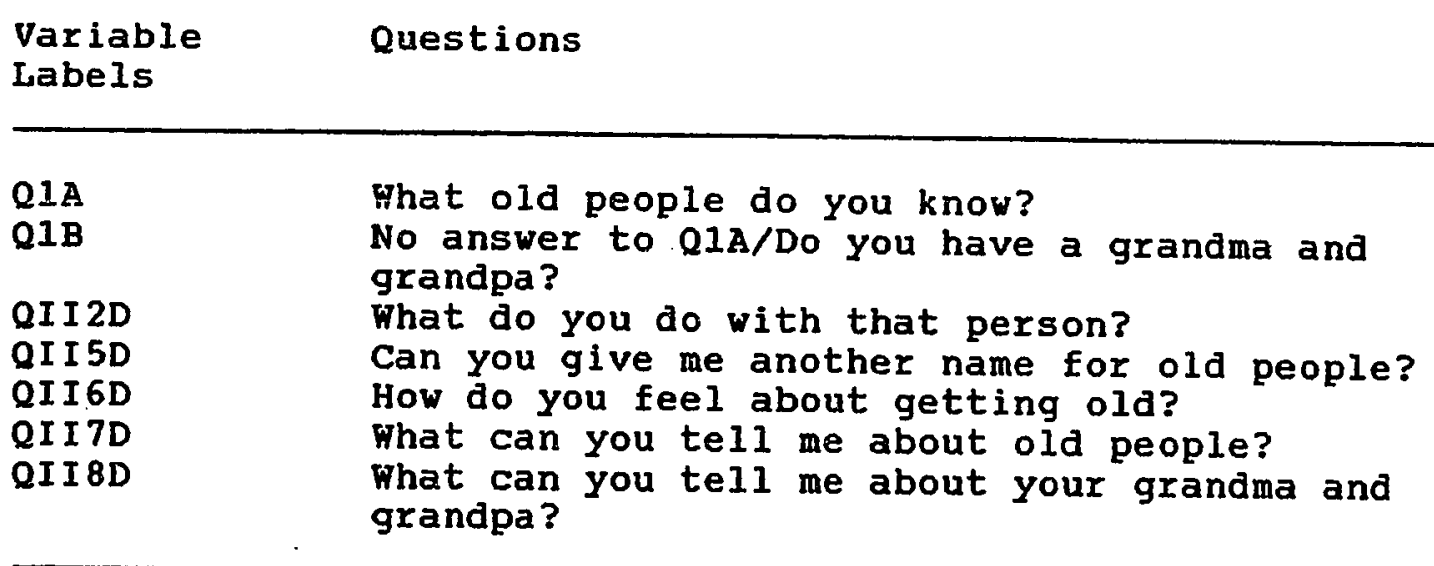

Table 2

Inter-coder Reliability Coefficients for Picture subtest and Mord Association subtest Categories

Variable Rellability Coefficient

\begin{tabular}{ll}
\hline QID & .9989 \\
Q2D & .8529 \\
Q3D & .8256 \\
QD4 & .6991 \\
GUES & .9812 \\
DISCRIM & .9421 \\
GRANG & .9667 \\
ARANG & .8514 \\
Q6D & .8893 \\
Q7D & .4235 \\
Q1A & .9612 \\
QIB & .8969 \\
QII 2D & .7957 \\
QII5D & .9093 \\
QII6D & .7782 \\
QII 7D & .8268 \\
QII BD & .5743 \\
\hline
\end{tabular}


Chi-Square Analysis of Responses to CATE by Children from the Intergenerational Day Care Center and Conventional Day Centex

Chi-square analyses were computed in order to detect significant differences among the intergenerational day care center and the conventional day care centers in relation to the types of responses the children gave to the CATE picture series questions and word association questions. Results indicated that the children significantly differed on only four questions.

The children in the intergenerational day care center $(\underline{n}=21)$ differed significantly from those in the conventional day care centers $(\underline{n}=22)$ in their perception of which person they thought was the oldest in the two pictures $\left[\chi^{2}(1, N=43)=4.53, \mathrm{~N}<.05\right]$. The children From the intergenerational day care center were more likely to perceive age accurately than those from the conventional day care centers. Eighty percent of the children in the intergenerational day care center thought that the grandmother was the oldest, while only $50 \%$ of the children from conventional day care centers thought the grandmother was the oldest.

The children in the two types of day care centers also differed significantly in their types of responses given to the question which asked, "How will you feel when you are that old?" $\left[X^{2}(9, \mathbb{N}=43)=15.98, \underline{p}<.10\right]$. The children 
differed in that the children in the intergenerational day care center used nine of the categories, while the children from the conventional day care centers used only four of the categories. However, neither sample of children provided a significant number of negative or positive responses to this guestion. In fact, the children's responses are guite similar when the inappropriate responses are observed. The responses of the children in the intergenerational day care center consisted of 57.18 inappropriate answers, and 59.18 of responses from the children in the conventional day care centers were considered inappropriate answers.

Another significant difference reported between children in the two types of day care centers was in their responses to the question, "What things would you help this person do?" $\left[X^{2}(10, \underline{N}=43)=17.59, \mathrm{E}<.10\right]$. Again, this was due to the fact that the children in the Intergenerational day care center used more categories than the children in the conventional day care centers. When the inappropriate answers and activity categories are combined, the frequencies are similar. The responses of the children in the intergenerational day care center consisted of $52.3 \%$ activity related, 23.88 inappropriate answers, 9.58 affective, and 4.88 quasi-scientific, role related, and violent. The responses of the children in the conventional day care centers were comprised of 40.98 inappropriate answers and $59.1 \%$ activity related. 
The last statistically significant finding was on the question, "How old do you think each of these women are?" $\left[X^{2}(1, \underline{N}=43)=2.98, p<.10\right]$. The children in the conventional day care centers were more likely to discriminate accurately between old and young in terms of the ages they provided. Over $50 \%$ of the children in the conventional day care centers correctly discriminated between the two women, while only $28 \%$ of the children in the intergenerational day care center were able to correctly discriminate. Both groups of children did poorly on the age ranges. The correct age range percentages for the children in the conventional day care centers were 22.78 for the grandmother and $31.8 \%$ for the aunt. The correct age range percentages for the children in the intergenerational day care center were 198 for the grandmother and $9.5 \%$ for the aunt. It was discovered that only one of the children from the intergenerational day care center, and only five of the children from the conventional day care centers gave both the correct age ranges and discrimination. Although there were only four guestions in which the two groups differed significantly, there were several non-significant findings that have important theoretical implications. One interesting finding was in the results to the question, "Which person would you prefer to be with?" The majority of the children from both groups ( $76.2 \%$ intergenerational, $77.3 \%$ conventional) preferred to be with the younger person. 
Another question which provided interesting results was "Why do you think the person you chose is the oldest?" The majority of the children from both groups could not give an appropriate response. The children in the intergenerational day care center presented 71.48 inappropriate answers, 9.58 subjective self, $4.8 \%$ affective, and only $14.3 \%$ why answers. The children in the conventional day care centers responded with $81.8 \%$ inappropriate answers, $4.5 \%$ affective, and only 13.68 why answers. These results showed that of the total population only 18.78 of the children could provide the type of responses that the original CATE scoring used.

The question which asked, "What old people do you know?" also provided some interesting information. First, only 52.48 of the children in the intergenerational day center and $50 \%$ of the children in the conventional day care centers were able to identify an old person. The majority of the children from both groups indicated grandparents. None of the children from the intergenerational day care center mentioned the teacher or aids at the center.

The follow-up question, "What do you like to do with that person?" also resulted in an interesting finding. The majority of the children from both groups were able to indicate a variety of activities in which they engaged.

One final interesting observation is that the children from both groups responded with more than four negative answers to only one question. The question was "How do you 
feel about getting old?" Forty-four percent of the children in the intergenerational day care center responded with negative adjectives, and 31.88 of the children in the conventional day care centers gave negative adjectives. However, the results in the other categories demonstrated that most of the children had problems answering the question. The children from the intergenerational group gave $33.3 \%$ inappropriate answers, $22.2 \%$ quasi-scientific, while the children from the conventional group responded with $40.9 \%$ inappropriate answers, $13.6 \%$ quasi-scientific, 98 positive adjectives, and 4.58 domestic activity.

\section{Study II}

The data were analyzed using a sPSS/PC+ program (Norussis, 1988). First, the negative items on the life satisfaction scale, perceived contribution scale, talk about the past, present, and future scale, and the reminiscence scale were recoded. Second, reliability of the four scales was presented. Third, factor analyses, employing principal component analysis were conducted on all four scales. Fourth, multiple regressions were performed to investigate the impact of talk about the past, present, and future, on life satisfaction, perceived contribution, and functions of reminiscence.

Recode and Reliability

Nine seven-point items $(4,7,9,10,13,19,20,22$, 30) from the life satisfaction scale, two seven-point items 
(26, 30) from the perceived contribution scale, three sevenpoint items $(2,10,25)$ from the past, present, and future talk scale, and two five-point items $(7,24)$ from the reminiscence scale were recoded because the items were phrased negatively. For the four scales, the higher the score the more positive the answer.

Reliabilities for the four scales were acceptable. The alpha coefficient for the 1 ife satisfaction scale was .80 . The perceived contribution scale had an a alpha coefficient of .60 . The alpha coefficient for the past, present, and future scale was .77 . Finally, the alpha coefficient for the reminiscence scale was .94 .

Principal Component Analyses

The first factor analysis was conducted on the six items which were added to discover to what degree the subject talked about the past, present, and future (see Table 3). Factors with an eigenvalue greater than 1.0 were extracted. One factor emerged that accounted for 47.18 of the variance (see Table 4). Since a one-factor solution was obtained, the factor could not be rotated. 
Table 3

Past, Present, and Future Talk Items

I2 There is nothing about the past I can talk about.

I6 There is a lot about the present I can talk about.

I10 There is nothing about the future I can talk about.

I21 There is a lot about the Euture I can talk about.

I25 There is nothing about the present I can talk about.

I31 There is a lot about the past I can talk about.

Table 4

Factor Analysis of Past, Present, and Future Talk Items

\begin{tabular}{lrrrrrrr}
\hline & & & & Eigen- & Pct of \\
Variable & Communality & $*$ & Factor & Cum \\
value & Var & Pct \\
I2 (PAST) & .52786 & $*$ & 1 & 2.82540 & 47.1 & 47.1 \\
I6 (PRESENT) & .28914 & $*$ & & & & \\
I10 (FUTURE) & .55166 & $*$ & & & & \\
I21 (FUTURE) & .60235 & $*$ & & & & \\
I25 (PRESENT) & .55699 & $*$ & & & & \\
I31 (PAST) & .29739 & $*$ & & & & \\
\hline
\end{tabular}

The one factor was named Talking items (see Table 5).

Table 5

Factor Matrix of Talk Items

\begin{tabular}{llr}
\hline & & FACTOR \\
I2 (PAST) & .72654 \\
I6 (PRESENT) & .53772 \\
I10 (FUTURE) & .74274 \\
I21 (FUTURE) & .77611 \\
I25 (PRESENT) & .74632 \\
I31 (PAST) & .54534 \\
\hline
\end{tabular}

The second factor analysis was conducted on the six perceived contribution items which were generated by the students (see Table 6). Two factors emerged that accounted 
for 55.48 of the varlance (see Table 7). In order to get a more parsimonious factor structure a varimax rotation was performed. Items that correlated higher than .40 with a factor were considered to be associated with that factor (see Table 8).

Table 6

Perceived Contribution Items

I24 I believe others can benefit from my life experiences.

I 26 At my age, I feel that I have nothing to contribute to society.

I27 I feel useful when I have responsibilities.

I 28 I feel that I'm doing all I can in order to fulfill my Iife.

I29 I feel that I play an important role in at least one other person's life.

I30 The most frustrating part of my life is that others will not let me do what I want to do.

Table 7

Factor Analysis of Perceived Contribution Items

\begin{tabular}{lrlcccc}
\hline & & & & Figen- & Pct of \\
Variable & Communality & $*$ & Factor & $\begin{array}{l}\text { Cum } \\
\text { value }\end{array}$ & Var & Pct \\
I24 & .68167 & $*$ & 1 & 2.26052 & 37.7 & 37.7 \\
I26 & .68615 & $*$ & 2 & 1.06108 & 17.7 & 55.4 \\
I27 & .37148 & $*$ & & & & \\
I28 & .47486 & $*$ & & & & \\
I29 & .42103 & $*$ & & & & \\
I30 & .68642 & $*$ & & & & \\
\hline
\end{tabular}


Table 8

Rotated Factor Matrix of Perceived Contribution Items

\begin{tabular}{|c|c|c|}
\hline & FACTOR 1 & FACTOR \\
\hline $\begin{array}{l}\text { I } 24 \\
\text { I } 26 \\
\text { I } 27 \\
\text { I } 28 \\
\text { I } 29 \\
\text { I } 30\end{array}$ & $\begin{array}{r}-.04159 \\
.78944 \\
.56480 \\
.22371 \\
.64886 \\
.82779\end{array}$ & $\begin{array}{r}.82458 \\
.25085 \\
.22908 \\
.65177 \\
-.00349 \\
-.03451\end{array}$ \\
\hline
\end{tabular}

The first factor ( $37.7 \%$ of the variance) composed of items $26,27,29$, and 30 , dealt with the perception of the subject's contribution in life. Factor one was, therefore, labeled Perceived Contribution. The second factor (17.78 of the variance) was not named because a meaningful category could not be interpreted.

The third factor analysis was conducted on the original Iife satisfaction items. Items $3,4,14,17$, and 19 were not included in the final factor analysis statistics (see Table 9).

Table 9

Deleted Life Satisfaction Items

I3 I have got more of the breaks in life than most people I know.

I4 This is the dreariest time of my life.

I 14 I feel my age, but it does not bother me.

I17 Compared to other people my age, I make a good appearance.

I19 when I think back over my 1 ife, I did not get most of the important things I wanted. 
Items 3, 14, and 19 were excluded, for it was suggested by Adams (1969) that items 3 and 19 did not measure what the content of the suggested, and item 14 did not correlate highly with any factor. Item 4, was excluded because the term "dreariest" was considered to be too extreme and the item did not correlate highly on any factor during a trial factor analysis. Item 17 was also excluded because it was concluded that the phrase "make a good appearance" was too vague.

The factor analysis was conducted on the 14 remaining life satisfaction items (see Table 10).

Table 10

Life Satisfaction Items Retained for Factor Analysis

I1 As I grow older, things seem bettex than I thought they would be.

I5 I am just as happy as when I was younger.

I7 My life could be happier than it is now.

I 8 These are the best years of my $11 \mathrm{fe}$.

I9 Most of the things I do are boring or monotonous.

I11 I expect some interesting and pleasant things to happen to me in the future.

I12 The things I do are as interesting to me as they ever were.

I13 I feel old and tired.

I15 As I look back on my 1 ife, I am fairly well satisfled.

I16 I would not change my past life even if I could.

I18 I have made plans for things I will be doing a month from now.

I20 I have not made plans for things I will be doing a year from now.

I 22 Compared to other people, I get depressed too often. I23 I have got pretty much what I expected out of 1 ife.

The factor analysis extracted five factors that accounted 
for $71.3 \%$ of the variance (see Table 11). A varimax rotation was used to get a more parsimonious factor structure. Items that correlated .40 or higher with a factor were considered to be associated with that factor (see Table 12).

Table 11

Factor Analysis of Life Satisfaction Items

\begin{tabular}{|c|c|c|c|c|c|c|}
\hline Variable & Communality & $\begin{array}{l}* \\
*\end{array}$ & Factor & $\begin{array}{l}\text { Eigen- } \\
\text { value }\end{array}$ & $\begin{array}{l}\text { Pct of } \\
\text { Var }\end{array}$ & $\begin{array}{l}\text { Cum } \\
\text { Pct }\end{array}$ \\
\hline $\begin{array}{l}I 1 \\
I 5 \\
I 7 \\
I 8 \\
I 9 \\
I 11 \\
I 12 \\
I 13 \\
I 15 \\
I 16 \\
I 18 \\
I 20 \\
I 22 \\
I 23\end{array}$ & $\begin{array}{r}.76544 \\
.77229 \\
.45010 \\
.78543 \\
.76684 \\
.59656 \\
.69573 \\
.79439 \\
.80191 \\
.70071 \\
.67782 \\
.74135 \\
.75703 \\
.67199\end{array}$ & $\begin{array}{l}* \\
* \\
* \\
* \\
* \\
* \\
* \\
* \\
* \\
* \\
* \\
* \\
* \\
*\end{array}$ & $\begin{array}{l}1 \\
2 \\
3 \\
4 \\
5\end{array}$ & $\begin{array}{l}4.14445 \\
2.18151 \\
1.38269 \\
1.17700 \\
1.09195\end{array}$ & $\begin{array}{r}29.6 \\
15.6 \\
9.9 \\
8.4 \\
7.8\end{array}$ & $\begin{array}{l}29 \cdot 6 \\
45 \cdot 2 \\
55.1 \\
63.5 \\
71.3\end{array}$ \\
\hline
\end{tabular}


Table 12

Rotated Factor Matrix of Life Satisfaction Items

\begin{tabular}{lrrr}
\hline & FACTOR 1 & FACTOR & \multicolumn{1}{l}{ FACTOR } \\
I1 & & & \\
I5 & .47073 & -.20564 & .60545 \\
I7 & -.02930 & .24062 & .82508 \\
I8 & .55545 & .04290 & .33563 \\
I9 & .13709 & .27499 & .76549 \\
I11 & .29286 & .40926 & -.06449 \\
I12 & .00226 & .55650 &. .38183 \\
I13 & -.10514 & .52335 & .13559 \\
I15 & -.29290 & -.01594 & .22336 \\
I16 & .49676 & .09761 & -.06944 \\
I18 & .82159 & -.00984 & -.09978 \\
I20 & -.04162 & .78250 & .15129 \\
I22 & .13856 & .84022 & .06730 \\
I23 & .15203 & .08561 & .29544 \\
\hline
\end{tabular}

Table 12

Rotated Factor Matrix of Life Satisfaction Items (continued)

\begin{tabular}{|c|c|c|}
\hline & FACTOR 4 & FACTOR 5 \\
\hline $\begin{array}{l}I 1 \\
I 5 \\
I 17 \\
I 8 \\
I 9 \\
I 111 \\
I 112 \\
I 13 \\
I 15 \\
I 16 \\
I 18 \\
I 20 \\
I 22 \\
I 23\end{array}$ & $\begin{array}{r}-.18015 \\
.14269 \\
.16394 \\
.30095 \\
.71196 \\
.11796 \\
.17134 \\
.59785 \\
-.04451 \\
.12493 \\
.12677 \\
.07983 \\
.79952 \\
.01768\end{array}$ & $\begin{array}{r}.32023 \\
.11142 \\
-.01457 \\
-.12031 \\
.05031 \\
.35658 \\
.60252 \\
.54866 \\
.73404 \\
.00556 \\
.15755 \\
-.07269 \\
.00887 \\
.07190\end{array}$ \\
\hline
\end{tabular}

Since items 1, 9, 12, 13, and 15 loaded on more than one factor, factors were not specifically named. Instead, each factor was labeled with the term Satisfy (see Table 13). 
Table 13

Life Satisfaction Factors

SATISFY $1=I 1+I 7+I 15+I 16+I 23$

SATISFY $2=I 9+I 11+12+I 18+I 20$

SATISFY $3=I 1+I 5+I 8$

SATISFY $4=I 9+I 13+I 22$

SATISFY $5=I 12+I 13+I 15$

Finally, the last factor analysis was performed on the reminiscence scale, which was designed to tap the functions served by monadic and dyadic reminiscing. However, two of the 26 original items $(3,14)$ dealt with frequency of reminiscing. Therefore, they were excluded from the analysis. A principal component analysis was conducted on the 24 remaining items. Five factors, accounting for 71.88 of the variance, emerged as result of the analysis (see Table 14). A varimax rotation was administered to retrieve a more parsimonious factor structure (see Table 15). 
Table 14

Factor Analysis of Reminiscence Items

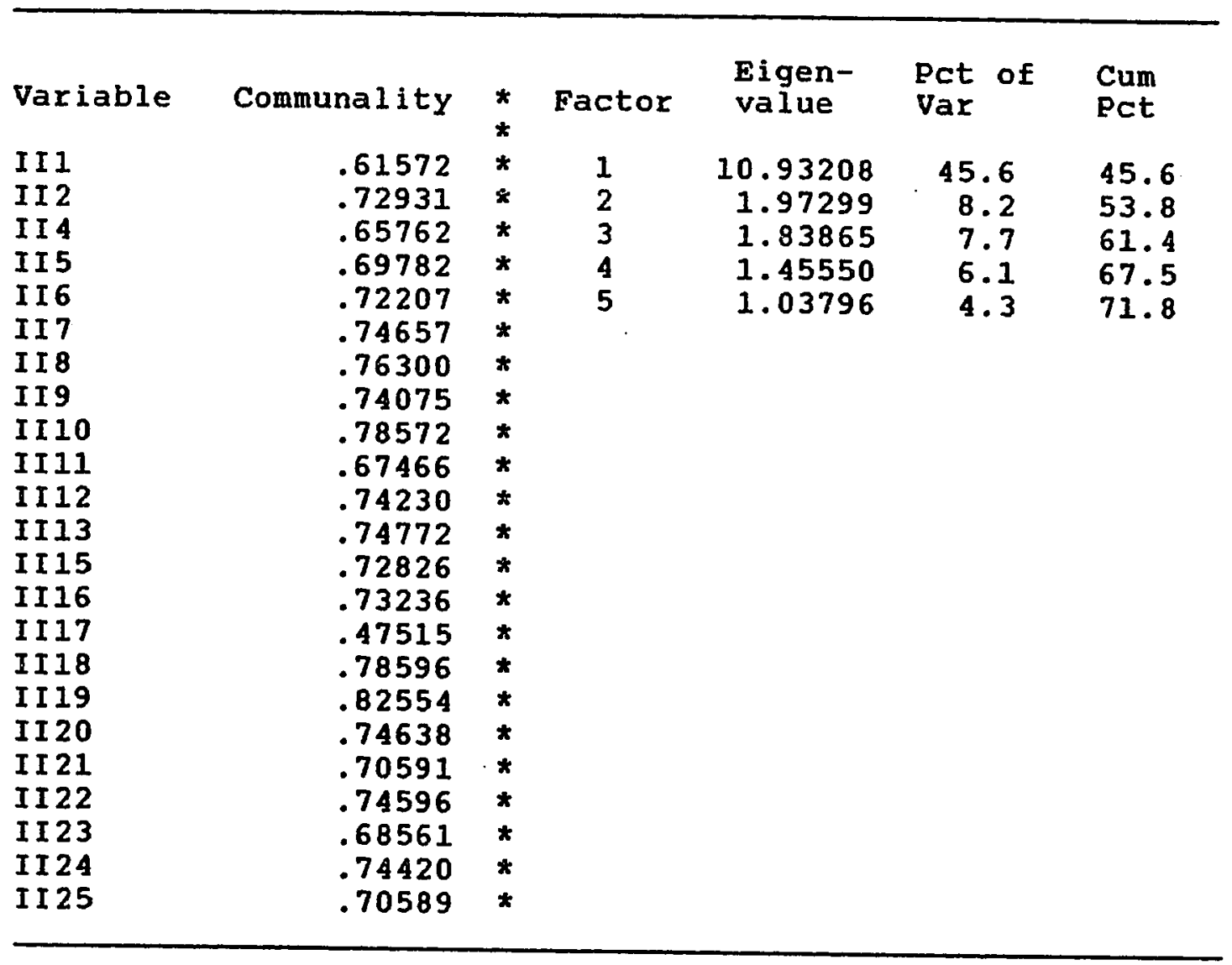


Table 15

Rotated Matrix of Reminiscence Items

\begin{tabular}{lrrrr}
\hline & FACTOR & & \\
& & FACTOR & 2 & FACTOR \\
III & .31122 & .08321 & .33409 \\
II2 & .01341 & .07134 & .79850 \\
II4 & .26576 & .11391 & .75502 \\
II5 & .69574 & .19739 & .39543 \\
II6 & .57574 & .25470 & .35676 \\
II7 & .11439 & .07361 & .16688 \\
II8 & .50920 & .28104 & .49012 \\
II9 & .80461 & .24128 & .18106 \\
II10 & .75729 & .24381 & .31215 \\
II11 & .27966 & .17347 & .75241 \\
II12 & .52603 & .38894 & .41051 \\
II13 & .30624 & .36662 & .64739 \\
II15 & .39430 & .63659 & .34181 \\
II16 & .17032 & .39654 & .69934 \\
II17 & .18526 & .60332 & -.02790 \\
II18 & .35097 & .73712 & .29653 \\
II19 & .20329 & .86480 & .14610 \\
II20 & .74210 & .42293 & -.03248 \\
II21 & .51229 & .44205 & .39946 \\
II23 & .19840 & .78694 & .12080 \\
II24 & .01321 & .06671 & .00689 \\
\hline
\end{tabular}

Table 15

Rotated Matrix of Reminiscence Items (continued)

\begin{tabular}{lrr}
\hline & FACTOR & FACTOR \\
III & 5 \\
II2 & -.06127 & .62973 \\
II4 & .21683 & .19856 \\
II5 & .03366 & -.05312 \\
II6 & .08701 & .10418 \\
II7 & .06944 & .44002 \\
II8 & .81359 & -.19566 \\
II9 & .01534 & -.42928 \\
II10 & .03709 & -.03128 \\
II11 & .23385 & -.02564 \\
II12 & .01544 & -.00249 \\
II13 & -.35906 & .12992 \\
II15 & -.00557 & .31683 \\
II16 & .18971 & -.12130 \\
& -.01850 & .23810 \\
\hline
\end{tabular}


Table 15

Rotated Matrix of Reminiscence Items (continued)

\begin{tabular}{lrr}
\hline & FACTOR & FACTOR \\
II17 & & \\
III8 & .02158 & -.27494 \\
II19 & .03972 & .17297 \\
II20 & -.08587 & .08728 \\
II21 & -.08096 & .09589 \\
II22 & -.29310 & .05077 \\
II23 & .28515 & .16658 \\
II24 & -.01831 & .10974 \\
\hline
\end{tabular}

Items that correlated .40 or higher with a factor were considered to be associated with that factor. The first factor (45.68 of the variance) was named Provides Comfort because it included items in which reminiscence was used to overcome a neutral or negative situation. For example, a neutral situation would be one where reminiscence was used for relaxation or a topic of conversation. A negative situation would be one where reminiscence was used to overcome boredom and loneliness. The second factor $18.2 \%$ of the variance) was named Gives Pleasure because it included items in which reminiscence was used to re-live happy memories and create good feelings. This function of reminiscence would be used for life enhancement. The third factor ( 7.78 of the variance), named Integrates, was defined by items in which reminiscence was used to understand or accept important and intense experiences. This function of reminiscence would be used as a form of self-psychology. 
The fourth factor ( 6.18 of the variance) was named Recode because it included the two negatively worded items which were recoded to receive a positive score. The fifth factor (4.38 of the variance) was not named because no basic variable could be identified. Table 16 lists the four functions of reminiscence and the items which defined them.

Table 16

Functions of Reminiscence

Provides Comfort

II5 Thinking about the past gives me relief from boredom.

II6 Talking about the past with another person helps me overcome a lonesome period.

II 8 Bringing up the past gives me something to talk about.

II Thinking about the past helps me relax and go to sleep.

II10 Thinking about the past helps me over a lonesome period.

II12 Thinking about the past helps me understand myself better.

II 20 Talking about the past with another person gives me relief from boredom.

II 21 Talking about the past with another person helps me understand myself better.

II26 Talking about the past with another person helps me relax and go to sleep.

Gives Pleasure

II15 Talking about the past with another person gives me a good feeling.

III7 I have someone to talk with about the past.

II18 Talking about the past with another person helps me to re-live a pleasant experience.

II19 Thinking about the past stirs up old memories.

II 22 Thinking about the past gives me a good feeling.

II 23 Talking about the past stirs up old memories.

II 25 Thinking about the past helps me to re-live a pleasant experience. 
Table 16

Functions of Reminiscence (continued)

Integrates

II Thinking about the past helps me understand young people better.

II4 Thinking about the past helps me to get over a serious loss.

II8 Bringing up the past gives me something to talk about.

IIIl Talking about the past with another person helps me understand young people better.

II12 Thinking about the past helps me understand myself better.

II13 Talking about the past with another person helps me to get over a serious loss.

II16 Thinking about the past helps me accept changes.

Recode

II7 Thinking about the past gives me a bad feeling.

II24 Talking about the past with another person gives me a bad feeling.

\section{Regression Analyses}

The three talking variables, Past, Present, and Future, , were used as the predictor variables for life satisfaction. Five multiple regression analyses were conducted for Satisfy 1 to satisfy 5. Satisfy 2 was significantly predicted by Past, Present, and Future $\left[\underline{R}=.73, \underline{R}^{2}=.53, \underline{E}(3,60)=\right.$ 22.51, $\mathrm{E}<.0011$. The subsequent $\mathrm{t}$ tests indicated that Present $[\boldsymbol{B}=.26, \underline{t}(1,62)=2.18, \mathrm{p}<.05]$, and especially Future $[\beta=.55, \underline{t}(1,62)=4.89, \mathrm{e}<.001]$ were significant predictors of Satisfy 2. The variance of Satisfy 3 was accounted for significantly by Past, present, and Future $\left[\underline{R}=.38, \underline{R}^{2}=.14, \underline{E}(3,59)=3.29, \underline{D}<.05\right]$, but only present had a significant $t$ value $[\beta=.33, t \underline{\beta}(1$; 
$61)=2.01, \mathrm{D}<.051$. The regression analysis with satisfy 4 as the criterion variable was extremely significant $I R=$ $\left..65, \underline{\mathrm{R}}^{2}=.42, E(3,61)=14.91, \mathrm{E}<.001\right]$, and Past $[\boldsymbol{\beta}=$ $-.23, \pm(1,63)=-1.96, \mathrm{D}=.05]$, Present $[\boldsymbol{\beta}=.41, \pm(1$, $63)=3.09, \underline{D}=.003]$, and Future $[\beta=.43, \underline{E}(1,63)=$ $3.44, \mathrm{p}=.001 \mathrm{~J}$ each reached significance in the subseguent t tests. The overall regression reached significance for Satisfy $5\left[R=.48, \underline{R}^{2}=.23, \underline{F}(3,61)=6.25, \underline{D}<.001\right]$, but among the three variables only Future reached significance as predictor of life satisfaction $[\boldsymbol{\beta}=.42$, $\underline{t}(1,63)=2.9, \mathrm{p}<.011$.

A stepwise multiple regression analysis was conducted with Past, Present, and Future as the predictor variables for Perceived Contribution. Perceived Contribution was significantly predicted by the three predictor variables $\left[\underline{R}=.77, \underline{R}^{2}=.59, \underline{E}(3,60)=28.94, \underline{D}<.001\right]$, but it was present $[\beta=.27, \underline{t}(1,62)=2.4, \underline{\mathrm{L}}<.05]$ and more importantly Future $[\boldsymbol{\beta}=.48, \underline{t}(1,62)=4.6, \mathrm{Q}<.001]$ that had significant $\underline{t}$ values on Perceived Contribution.

Four stepwise multiple regression analyses were also performed to further investigate the impact of talk about the past, present, and future on the functions of reminiscence. Past, Present, and Future accounted significantly for the variance of Provides Comfort $[\underline{R}=.47$, $\underline{\mathrm{R}}^{2}=.22, \underline{E}(3,61)=5.82, \mathrm{D}<.0011$. Further analysis indicated that the individual contribution of Past was 
significant on Provides comfort $[\boldsymbol{\beta}=.49, \underline{t}(1,63)=3.61$, L $<.001]$, while Present and Future failed to reach significance. The variance of Gives pleasure was also accounted for significantly by Past, Present, and Future $\left[\underline{R}=.46, \underline{R}^{2}=.22, \underline{E}(3,61)=5.60, \underline{D}<.01\right]$. The $\underline{t}$ tests indicated that only Past was the significant contributor on Gives Pleasure $\{\boldsymbol{\beta}=.41, \underline{t}(1,63)=2.99, \mathrm{p}<.01\}$. For Integrates, Past, Present, and Future accounted significantly for the variance $\left[\underline{R}=.45, \underline{R}^{2}=.20, E(3,61)=\right.$ 5.11 , $\mathrm{p}<.01]$, but among the three variables, only Past reached significance $[\beta=.43, t(1,63)=3.15, \mathrm{Q}<.01]$. 


\section{CHAPTER IV}

Results and Discussion

\section{Study I}

The purpose of the first study was to explore children's attitudes toward aging and elderly people by studying specifically children in an intergenerational day care center and three conventional day care centers. The research question was: Do children in an intergenerational day care center have different attitudes toward aging and elderly people from those in conventional day care centers? The results indicated that the children in the intergenerational day care center did not differ from the children in the conventional day care centers in their attitudes toward aging and elderly people. More importantiy, results suggested that the children did not have a conceptual understanding of aging at all. This finding is very important because if preschool children do not understand the concept of aging, they cannot give accurate responses to questions which test attitudes toward aging and the elderly.

One contradiction which resulted from two statistical analyses can be used to substantiate the assertion that these children did not have a conceptual understanding of aging. At first it was assumed that the children from the intergenerational day care centex understood the concept of aging better than the other children, since they were more 
likely to choose the grandmother as the older of the two women. However, this assumption was refuted immediately in the subsequent analyses. The children from the conventional day care centers were more likely to discriminate between the two women when asked the question related to specific ages. In fact, further analyses showed that the majority of both groups of children failed to provide the correct age ranges and discriminations. In other words, the children could sometimes answer with the correct ordering or correct age range, but they did not have a conceptual understanding of age in order to be correct on both categories.

The fact that many of the children from both groups could not answer some of the questions also suggests that preschool children do not understand the concept of aging. For example, when the children were asked how they would feel when they were as old as the woman in the picture, over half of the children from both groups were unable to provide an appropriate response. The same was true for the question that asked, "Why do you think the person you chose is the oldest?" Most of the children from both groups could not give a reason. This finding is surprising since the developers of the original CATE suggested that children are able to provide more information when a concrete object is used to elicit responses. The most responses were provided to the questions that referred specifically to the activities that the children did with their grandparents. 
Since this question allowed the children to retrieve information from their own concrete experiences, the children were able to name a variety of activities.

Although the children could explain the activities they did with their grandparents, most of them could not describe how they felt about getting old. This suggests that

children can talk about what they have experienced, but they cannot express how they will feel about something which has not happened to them. The negative responses which were given are subject to question since most of the children did not understand the meaning of growing old.

Intergenerational contact implications. The suggestion that preschool children do not understand the concept of aging has implications for further intergenerational contact involving preschool children. It was discovered that the children at the intergenerational day care center did not associate their caretakers with being old. If the children do not think of their caretakers as older people, how can we assume that the contact is going to develop more positive attitudes toward aging and older people? The contact with the caretakers did not influence the children's preference when they had to choose to be with the older woman or younger woman. The majority of the children from the intergenerational day center and conventional day care centers preferred to be with the younger person. To further investigate the impact the caretakers have on the children 
it would be interesting to ask which person they would like to have as a teacher?"

The results of this study indicate that mere contact with an older caretaker does not provide children with more positive attitudes toward older people and aging. The children did not recognize a relationship between growing old and the caretakers. If intergenerational day care centers want to talk about growing old they need to make a connection between the caretakers and grandparents, since half of the children considered their grandparents as old persons. The few children who indicated negative responses toward growing old talked about grandparents who were sick or dead. If these children were given a more positive and functional example of an older person, they might be able to form a more positive attitude toward aging.

Theoretical Implications. The main theoretical implications gained from this study are in the area of language and cognitive development. The high frequency of low level answers provided by the children can be explained from the Vygotskian theoretical perspective. Since these children did not illustrate a conceptual understanding of age it can be speculated that these children were at the early levels of cognitive development. The syncretic stage of cognitive development can be used to explain the presence of irrelevant, subjective, and affective responses. As stated previously, at this stage the child's thinking is 
irrational and emotional. The irrelevant answers appeared to be irrational, for the responses did not connect with the questions. In the case of the subjective responses, the child based his or her answer on the feeling that he or she gave the correct answer rather than on logic. The affective responses were also derived from emotion. This was exemplified when the child used an affective response as a reason for choosing one of the women as the oldest. The child's selection was not based on physical features, but rather on the impression of whether he or she liked the person.

The fact that the children consistently gave both appropriate and inappropriate answers suggests complexive thinking. This was especially apparent in their responses to the question concerning the age of each of the women. For example, a child would say that the older woman was the oldest, yet the child would say she was four years old, or the child would say that the older woman was eighty and then say the younger woman was ninety. These responses depict the phenomenon referred to by Vygotsky as a pseudoconcept because at first the child appears to understand the concept, but further examination suggests otherwise.

The prevalence of activity oriented responses also suggests complexive thinking. In the complexive stage the child can talk about the concrete. This was clearly demonstrated by the children's ability to talk in great 
detail of what they liked to do with their grandparents. Study II

The purpose of the second study was to examine the life satisfaction, perceived contribution, and functions of reminiscence of elderly people and their talk about the past, present, and future. The results indicated that talking about the past does not generally predict life satisfaction. Talking about the present and future were significantly related to satisfy 2 . Satisfy 3 was significantly predicted solely by talking about the present, and Satisfy 5 was only predicted by talking about the future. Satisfy 4 was predicted by talking about the past, present, and future, but again Present and Future were the leading contributing factors. These results suggest that being able to talk about the present and future is important in achieving life satisfaction in the aging process.

Analyses were also conducted to determine whether or not talking about the past was related to the different functions of reminiscence. The regression model revealed that Provides Comfort, Gives Pleasure, and Integrates were significantly explained by talking about the present, talking about the past, and talking about the future. However, only talking about the past was a predictor related significantly to each use of reminiscence. This finding could be attributed to the fact that the vord "past" was stated clearly in each of the questions. It should be noted 
that in the literature about aging and communication, reminiscence can be both functional and dysfunctional. These results suggest that talking about the past is used for a variety of functions.

Although talking about the past was a predictor for the reminiscence functions, this study concluded that it was not a predictor of Perceived Contribution. A feeling of usefulness in society was predicted by talking about the present and even more significantly predicted by talking about the future. These results may explain why obsessive reminiscence can be dysfunctional. If an older person can not talk about the present or more importantly the future, he or she may not be able to sustain a sense of personal worth in society.

Theoretical implications. The main theoretical thrust of this study lies in the area of Activity Theory. The results support the Activity theoretical perspective because the older people indicated that they were more satisfied with their lives and felt more functional in society when they were able to talk about the present and future. Talking about the past served a variety of important functions, but it did not necessarily lead to life satisfaction. This $f$ inding seems to support the Activity Theory, because activities can enhance the communication process. The elderly that are engaged in social activities and organizations will have more of an opportunity to talk 
about the present and future since these activities generally require community involvement.

Talking about the past was a weak predictor of Perceived Contribution and Life Satisfaction. In other words, the Disengagement Theory was not favored because it failed to relate to a positive aging process.

overall Conclusions

Limitations. This research is an initial attempt to explore the old and the young together in relation to the aging process. However, several limitations in both studies need to be acknowledged. One limitation of the children's study was the small sample size. Since intergenerational day care centers are unique, it is difficult to find a large number of children from this type of center. In order to generalize these findings, more children from the intergenerational setting need to be interviewed.

Another limitation of this study was the survey instrument. First, administering the instrument took longer than the estimated fifteen minutes because of the added questions. Children frequently lost interest and responded quickly so they could go back to their activities. In the future, the number of questions needs to be reduced, or the two subtests should be given on separate occasions. The second limitation of the instrument was that too many abstract questions were used. The instrument needs to contain more concrete questions which refer to the 
children's own experiences. The final limitation of the instrument was the use of new categories. The new categories need to be more refined so they can be collapsed and further tested for validity and reliability.

There were also limitations to the elderly study. One limitation of this study was the sample. A larger and more. diverse sample is needed before any generalizations can be made. A study needs to be conducted on both active and nonactive elderly in order to make a more substantial claim on the importance of talking about the present and future. The sample needs to be more diverse in ethnicity since most of the respondents in this study were white. It can be speculated that most of the respondents were at least middle class, since they lived in houses. A study including elderly people from different economic backgrounds may not provide the same results, since most lower income people cannot afford to be involved in many social activities.

Also noted was the limitation related to the instrument used. First, the questionnaire was too long. Some of the respondents suggested that it took them over thirty minutes to complete it. A shorter version of the questionnaire which focuses primarily on talking about the past, present, and future in relation to life satisfaction is needed. New questions which relate to life satisfaction need to be developed and tested since many of the questions "loaded" on more than one satisfaction factor. 
In addition to the specific limitations in the two separate studies, there was also one general limitation. The link between the two studies was relatively weak. In the future, studies need to be designed to examine actual communication processes between the young and the old.

Recommendations for further research. Further research is needed to study the young and the old in regard to the aging process. Additional research is needed to investigate children's development of thinking and speech in relation to their attitudes toward aging and elderly people. Research needs to be conducted with both preschool children and grade school children to examine the different levels of responses. This would help determine the age in which children begin to form attitudes about aging. This information could be used to design intergenerational programs that cultivate the seeds of positive attitudes toward the elderly.

The survey instrument used to investigate children's toward aging and elderly people could be improved if the questions were worded in terms of children's language. For example, instead of asking children, "Mhich person do you think is the oldest?", the researcher could ask, "Which person do you think is the grandma?" To test whether or not children associate old with being a grandma, the former question could be used as a follow-up question.

Additional research should continue exploring elderly's 
talk about the past, present, and future in relation to life satisfaction in various social and historical settings. If other studies find similar results, researchers could find themselves one step closer in suggesting how to age successfully. Studies also need to be conducted to explore gualitatively the activity systems of the elderly. Qualitative studies could provide insight to which activity systems promote engagement rather than disengagement. Furthermore, this will help determine which activity systems provide the best opportunities to talk about the present and future, and, consequently, increase life satisfaction for the elderly. Talking to the young is a form of activity. It may be a happy reengagement in life, after the elderly's disengagement from the activities of their early adulthood. However, other forms of reengagement must also be explored. Finally, efforts need to be devoted to examining the communication between the young and the old. Intergenerational day care centers, as well as other intergenerational contact need to be studied further, so we can learn how to make the experience richer for both the young and the old. For example, one of the benefits of intergenerational contact suggested in the literature review was the opportunity to teach children historical and cultural information. A more detailed qualitative approach might suggest ways in which talking about the past can bring generations closer together in the present and future. 


\section{REFERENCES}


REFERENCES

Adams, D. (1969). Analysis of a life satisfaction index. Journal of Gerontology, 24, 470-474.

American Association of Retired Persons. (1985). A profile of older Americans: 1985. Mashington, DC: Author.

Aristotle, (1927). Rhetoric. In W. D. Ross (Ed.) Aristotle Selections, (p. 324). Net York: Scribner's.

Becker, D. G., Blumfield, S., \& Gordon, N. (1984). Voices from the elghties and beyond: Reminiscences of nursing home residents. Journal of Gerontological Social Work, 8, B3-100.

Bennett, R., \& Eckman, J. (1973). Attitudes toward aging. In C. Eisoforfer \& P. Lawton (Eds.), The psychology of adult development and aging, (pp. 575-597). Mashington, DC: The American Psychological Association.

Berezin, M. (1972). Psychodynamic considerations of aging and the aged: An overview. American Journal Psychiatry, 128, 1483-1491.

Bley, N. B., Goodman, M., Dye, D., \& Haiel, B. (1972). Characteristics of aged participants in age segregated leisure programs. Gerontologist, 12, 388-370.

Brotman, H. (1974). The fastest growing minority: The aging. American Journal of Public Health, 64, 249-252.

Burgess, E. W. (1954). Social relations, activities, and personal adjustment. American Journel of Sociology, 59, $352-360$.

Butler, R. N. (1963). The life review: An interpretation of reminiscence in the aged. Psychiatry, 26, 65-76.

Butler, R. N. (1968). The life review: An interpretation of reminiscence in the aged. In $B$. Neugarten (Ed.), Middle age and aging (pp.486-496). Chicago: University of Chicago press.

Chappe1, G. (1977). The effect of frequent ongoing contact with an old person on young children's attitudes toward the elderly (Doctoral dissertation, The American University, 1977). Dissertation Abstracts International, 38, 2850B. 
Cumming, E. (1963). Eurther thoughts on the theory of disengagement. International Social Science Journal, 15 , $377-393$.

Cumming, E., Dean, L., Newell, D., \& McCaffrey, I. (1960). Disengagement tentative theory of aging. sociometry, 23, 23-35.

Cumming, E., \& Henry, W. E. (1961). Growing old. New York: Basic Books.

Cutler, N. (1973). Age variations in the dimensionality of ife satisfaction. Journal of Gerontology, 28, 96-100.

Dinkel, R. (1944). Attitudes of children toward supporting aged parents. American sociological Review, 2, 370-379.

Georgemiller, R., \& Maloney, H. (1984). Group Iife review and denial of death. Clinical Gerontologist, 2 (4), 3749 .

Gubrium, J. F. (1973). The myth of the golden years: A socio-environmental theory of aging. Springfield, IL: Charles C Thomas.

Graves, R. (1955). The greek myths. Baltimore, MD: Penguin Books.

Haight, R., \& Baur, R. T. (1984). The therapeutic role of the life review in the elderly. Academic Psychology Bulletin, 6 , 287-299.

Havighurst, R. J., \& Glasser, R. (1972). An exploratory study of reminiscence. Journal of Gerontology, 27, 245253 .

Havighurst, R. J., Neugarten, B. L., \& Tobin, S. S. (1968). Disengagement and patterns of aging. In $B$. L. Neugarten (Ed), Middle age and aging (pp. 161-172). Chicago, ILL: University of Chicago Press.

Hickey, T., Hickey, L., \& Kalish, R. (1968). Children's perceptions of the elderly. Journal of Genetic Psychology, 112, 227-235.

Immorilica, A. G. (1980). The effect of intergenerational contact on children's perceptions of old people (Doctoral dissertation, University of Southern California, 1980). Dissertation Abstracts International, 40, 5621B. 
Jantz, R. K., Seefeldt, C., Galper, A., \& Serock, K. (1976). Children's attitudes toward the elderly: Final report. College Park, MD: University of Maryland.

Kaminsky, M., (1984a). The uses of reminiscence: A discussion of the formative literature. Journal of Gerontological Social Fork, I, 137-156.

Kaminsky, M., (1984b). Transfiguring life: Images of continuity hidden among the fragments. Journal of Gerontological Social Work, 7, 3-18.

Kastenbaum, R., \& Durkee, N. (1964). Young people view old age. In R. Kastenbaum (Ed.), New thoughts on old age (pp. 237-249). New York: Springer.

Kațman, R., \& Carasu, T. (1975). Differential diagnosis of dementia. In $W$. Fields (Ed.), Neurological and sensory disorders in elderly. Mami, FL: Specialist Books.

Kiernat, J. M. (1983). Retrospection as a life span concept. Physical and Occupational Therapy in Geriatrics, $\underline{3}$ (2), 35-48.

Klausmeier, H., \& Ripple, R. (1974). Learning the human abilities. New York: Harper and Row Publishers.

Kramer, \& Bumgarner (1985). Working together: Training lowincome elderly for work in child care. In $K$. A. Struntz \& S. Reville (Eds.), Growing together: An intergenerational sourcebook (pp. 18-22). Washington, DC: American Association of Retired Persons.

Langer, E. (1983). The psychology of control. Deverly Hills, CA: Sage.

Larson, R. (1978). Thirty years of research on the subjective well-being of older Americans. Journal of Gerontology, 33, 109-124.

Lebo, D. (1953). Some factors said to make for happiness in old age. Journal of Clinical Psychology, 9 , 384-390.

Lemon, B. W., Bengston, V. L., \& Peterson, J.A. (1972). An exploration of the activity theory of aging: Activity types and life satisfaction among in-movers to a retirement community. Journal of Gerontology, 27, 511523. 
Lesser, J., Lazaras, L. W., Frankel, R., \& Harasy, S. (1981). Reminiscence group therapy with psychotic geriatric patients. The Gerontologist, 21, 291-296.

Levin, J., \& Levin, W. C. (1981). Willingness to interact with an old person. Research on Aging, $\underline{3}, 211-217$.

Lyons, C., Newman, S., \& Vasudez, J. (1985). The impact of a curriculum on aging on elementary school students. In $k$. A. Struntz \& S. Reville (Eds.), Growing together: An intergenerational sourcebook (pp. 18-22). Washington, DC: American Association of Retired Persons.

McTavish, D. G. (1971). Perceptions of old age: A review of research methodologies and findings. Gerontologist, 11, 90-101.

Neugarten, B. L., Havighurst, R. J., \& Tobin, S. S. (1961). The measurement of life satisfaction. Journal of Gerontology, 16, 134-143.

Neugarten, B. L., Havighurst, R. J., \& Tobin, S. S. (1968). Personality and patterns of aging. In $B$. I. Neugarten (Ed.), Midale age and aging (pp. 173-177). Chicago, IL: University of Chicago Press.

Newman, S. (1985). The impact of intergenerational programs on children's growth and on older persons' life satisfaction. In K. A. Struntz \& S. Reville (Eds.), Growing together: An intergenerational sourcebook (pp. 22-24). Washington, DC: American Association of Retired Persons.

Newman, S. Baum, M.; \& Vasudez, J. (1983). The expexience of senior citizen volunteers in intergenerational programs in schools and the relationship to their life satisfaction: Final report. Pittsburgh, PA: Generations Together of University of Pittsburgh.

Nuessel, F. H. (1982). The language of ageism. The Gerontologist, 22, 273-276.

Nussbaum, J. F. (1981). Interactional patterns of elderly individuals: Implications for successful adaptation to aging. Unpublished doctoral dissertation, Purdue University, Fest Lafayette, IN.

Nussbaum, J. F. (1983a). Perceptions of communication content and life satisfaction among the elderly. Communication Quarterly, 31, 313-319. 
Nussbaum, J. F. (1983b). Relational closeness of elderly interaction: Implications for life satisfaction. Western Journal of Speech Communication, 47, 229-243.

Nussbaum, J. F., Thompson, T., \& Robinson, J. D. (1989). Communication and aging. New York: Harper \& Row.

Page, S. (1981). Children's attitudes toward the elderly and aging. Educational Gerontology: An International Quarterly, $7,43-47$.

Palmore, E. B. $(1982)$. Attitudes toward the aged: What we know and need to know. Research on Aging, 4, 333-348.

Pershbacher, R. (1984). An application of reminiscence in an activity setting. The Gerontologist, 24, 343-345.

Priefer, B. A., \& Gambert, S. R. (1984). Reminiscence and life review in the elderly. Psychiatric Medicine, $2,91-$ 100 .

Reichard, S., Livson, F, \& Peterson, P. G. (1962). Aging personality. New York: Guilford Press.

Seefeldt, C. (1984). Children's attitudes toward the elderly: A cross-cultural comparison. International Journal of Aging and. Human Development, 19, 319-328.

Seefeldt, c. (1983). Children's attitudes toward the elderly: Paraguay and the United States. International Journal of Comparative Sociology, 23, 40-53.

Seefeldt, C., Jantz, R. K., Galper, A., \& Serock, K. (1977). Children's attitudes toward the elderly: Final report. College Park, MD: University of Maryland.

Seefeldt, C., Jantz, Serock, K., Galper, A. (1977). Children's attitudes toward the elderly: a study of curriculum implementation. College Park, MD: University Press.

Seefeldt, C., \& Tafoya, E. (1981). A cross-cultural study of children's attitudes towards the elderly: Alaska native and mainland United States. International Journal of Social Psychology, 11, 15-24.

slater, P. E. (1964). Cross-cultural views of the aged. In R. Kastenbaum (Ed.), New thoughts on old age (pp. 229236). New York: Springer. 
Struntz, K. A., \& Reville, S. (Eds.). (1985). Growing together: An Intergenerational sourcebook. Washington, DC: American Association of Retired Persons.

Tamir, L. M. (1979). Communication and the aging process: Interaction throughout the life cycle. New York: Pergamon Press.

Tobin, S. S., \& Neugarten, B. L. (1961). Life satisfaction and social interaction in aging. Journal of Gerontology, 16 , 344-346.

Trent, C., \& Glass, J. C. (1985). The development and evaluation of a series of educational experiences designed to effect changes in adolescents' attitudes toward the aged. In K. A. Struntz \& S. Reville (Eds.), Growing together: An intergenerational sourcebook (pp. 35-37). Washington, DC: American Association of Retired Persons.

Tuckman, F., \& Lorge, I. (1953). Attitudes toward old people. Journal of Social Psychology, 37, 249-260.

Tuckman, F., \& Lorge, I. (1956). Perceptual stereotypes about 1 ife adjustment. Journal of Social Psychology, 43, 239-245.

Vygotsky, L. S. Thinking and speech. In R. W. Rieber \& A. S. Carton (Eds.), The collected works of L.S. Vygotsky: Vol. 1 Problems of general psychology (pp. 43-285). New York: Plenum.

Wingard, J. A. (1982). The effects of contextual variations on attitudes toward the elderly. Journal of Gerontology, 37, 475-482. 
APPENDIXES 
APPENDIX A

ORIGINAL CATE QUESTIONNAIRE AND CATEGORIES 
ORIGINAL CATE QUESTIONNAIRE AND CATEGORIES

Word Association Subtest

1. What can you tell me about old people?

Affective: Feelings about older people that are expressed by comments such as "they're nice, mean, kind," or "I like them."

Physical: Responses that pertain to physical attributes or personal appearance such as "they have wrinkles," "gray hair," "glasses," or "they wear pretty clothes."

Behavioral: Answers that describe characteristics based upon life styles of older people, including specific behaviors. Included under this category are things the older person has and things he does. Typical responses might be old people "have money," "dogs," "old houses," or "they walk funny," "they die," "they don't go out much."

In addition, within each category the degree of positiveness or negativeness is measured by rating a specific response as either positive or negative.

Affective Positive: Responses could include "they're nice," "I like them." Affective Negative: "they're mean," "nasty," "I don't like them."

Physical Negative: "they have wrinkles," "gray hair," "walk with crutches." (Positive examples were not indicated)

Behavioral Negative: "they walk with crutches" (Positive examples were not indicated)

2. What old people do you know?

Family: Yes No

Others: Yes No

3. What do you do with that person?

With-active: Responses indicating joint active or moving participation between subjects and the older person. Activities could involve going places, playing games, other than board games such as checkers or 
chess, and doing things with each other such as cooking and planting gardens.

With-passive: Responses referring to a quiet activity such as talking, reading, watching T.V., playing checkers with children and an older person doing something together of a quiet, passive nature.

For: Responses that portray either the subject, or the older person doing something for the other person. For example if the older person is seen as "cooking for me," "giving me presents," "lets me visit him," or the younger person "clean the older person's house for him," "goes to the store for him," or helps in some way where the action is on the part of only one of the parties.

4. Can you give me another name for old people?

Yes - correct responses such as elderly, senior citizen etc.

No - the subject is given a "no" score if he does not respond or the response is not appropriate, i.e., aunt, grandmom, George Washington.

5. How do you feel about getting old?

Positive: The subject may look forward to getting old or give some indication that he/she feels good about it.

Neutral: Responses that are global such as "it's okay" or responses that imply one has little control over getting old because it's just the scheme of things. A child might say "There's not much I can do about it," or "That's the way it has to be."

Negative: Responses that reflect an aversion to getting old such as "I don't want to," "I'm going to stay young," "That's terrible," or "I'll feel sad," or "bad." 
Picture Questions

1. Which person do you think is the oldest? Why?

Evaluative: A response is considered evaluative if it refers to opinions or judgments, as made by the subject. Such responses would include, "she's nice," "mean," "sad," or "bad."

Physical-descriptive: Responses of this type would specifically relate to observable physical traits such as "she has gray hair," "wrinkles," or "her lips are pushed in."

2. How will you feel when you are that old? (Same categories as Question \#5 on Word Association Subtest)

3. What things would you help this person do? (child helping older person)

Affective: Responses pertaining to feeling or emotion where the child suggests that he would "be nice to" the older person or "love him."

Behavioral stereotype: Responses implying that the older person needs a great amount of help because of her age, such as "help her get well," "take her to the hospital," "help her walk," "clean up for her," or "take care of her."

Behavioral Unique: Responses that are rare in occurrence and depict helping the older person in unigue and different ways specific to the situation of the child. Examples of behavioral unique responses might be "I helped carry boxes when she moved," or "carrying wood for her fireplace."

4. What things could she help you do?

(older person helping child)

Affective: Responses such as "she could be nice to me" or "love me."

Behavioral stereotype: Responses indicating that "she could help me with my homework." 
5. How old do you think each of these woman are?

Age estimates given by each subject are recorded and used to determine mean-age estimates and standard deviations for the pictures.

6. Which of these people do you prefer to be with? Why?

Age-related: Any response specifically referring to age such as "she's older" or "she's younger."

Altruistic: Responses suggesting unselfish motivations and having the older person's interest in mind, i.e. "I want to take care of her," "she needs my help," or "I can make her better."

Evaluative: As defined in 1. Responses might include such comments as "I chose him because she's nice," "she's happy," "she's like my grandmother," "she's more active," "she can give me things."

7. What kinds of things could you do with that person? (Same as Question \#3 on Word Association Subtest) 
APPENDIX B

REVISED CATE QUESTIONNAIRE 


\section{REVISED CATE QUESTIONNAIRE}

\section{Picture Questions}

1. Which person do you think is the oldest?

Grandmother Aunt

Why?

2. How will you feel when you are that old?

3. What things would you help this person do?

4. What things could she help you do?

5. How old do you think each of these women are?

Grandmother Aunt

6. Which one of these women do you prefer to be with? Grandmother Aunt

Why?

7. What kinds of things could you do with that person? 
Word Association Questions

1. What old people do you know?

- Situation 1: Provided Answer

- Situation 2: Not provided/Asked about grandparents

2. What do you do with that person?

3. How often do you see that person?

4. Do you like being with that person?

5. Can you give me another name for old people?

6. How do you feel about getting old?

7. What can you tell me about old people?

8. What can you tell me about (Answer provided from \#1) 
APPENDIX C

REVISED PHOTOGRAPHS FOR PICTURE QUESTIONS 
REVISED PHOTOGRAPHS FOR PICTURE QUESTIONS

\section{Year old Mother}

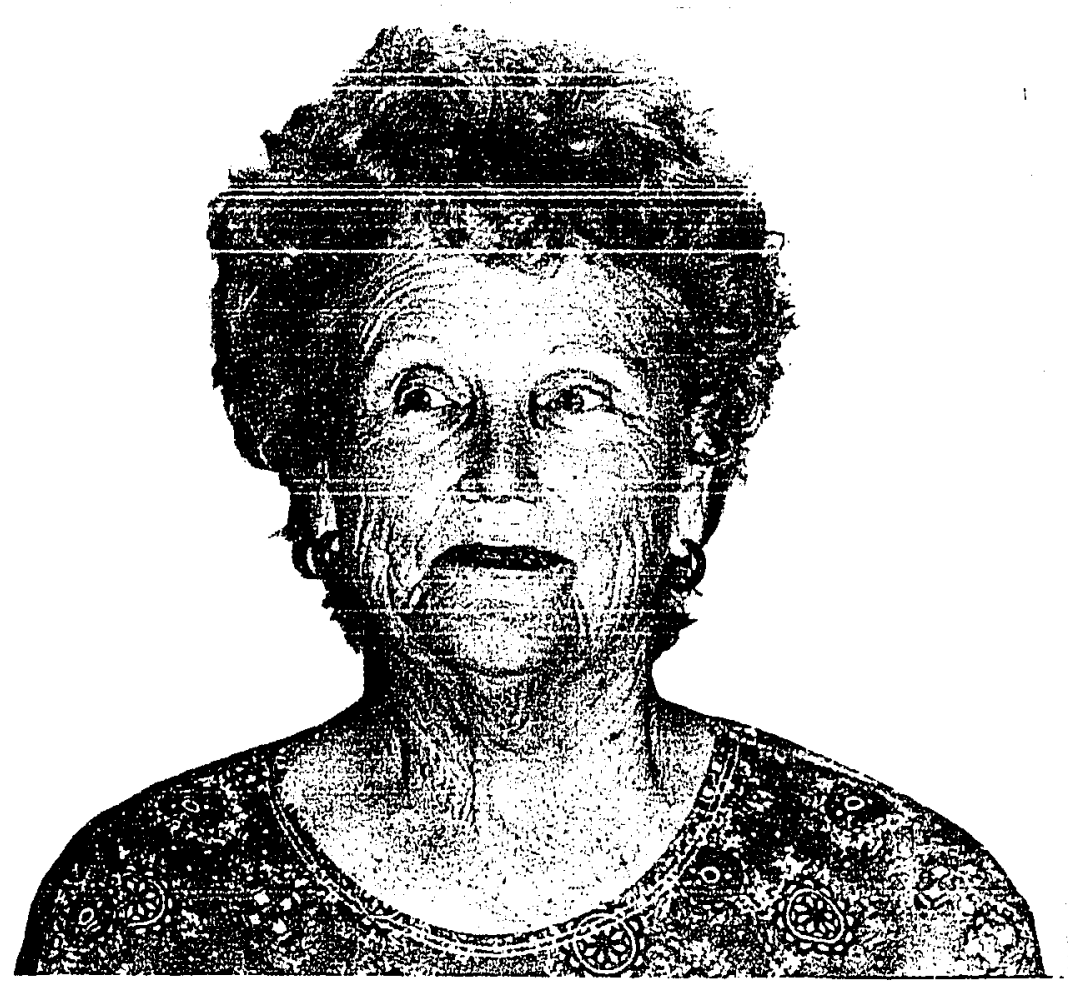

37 Year Old Daughter

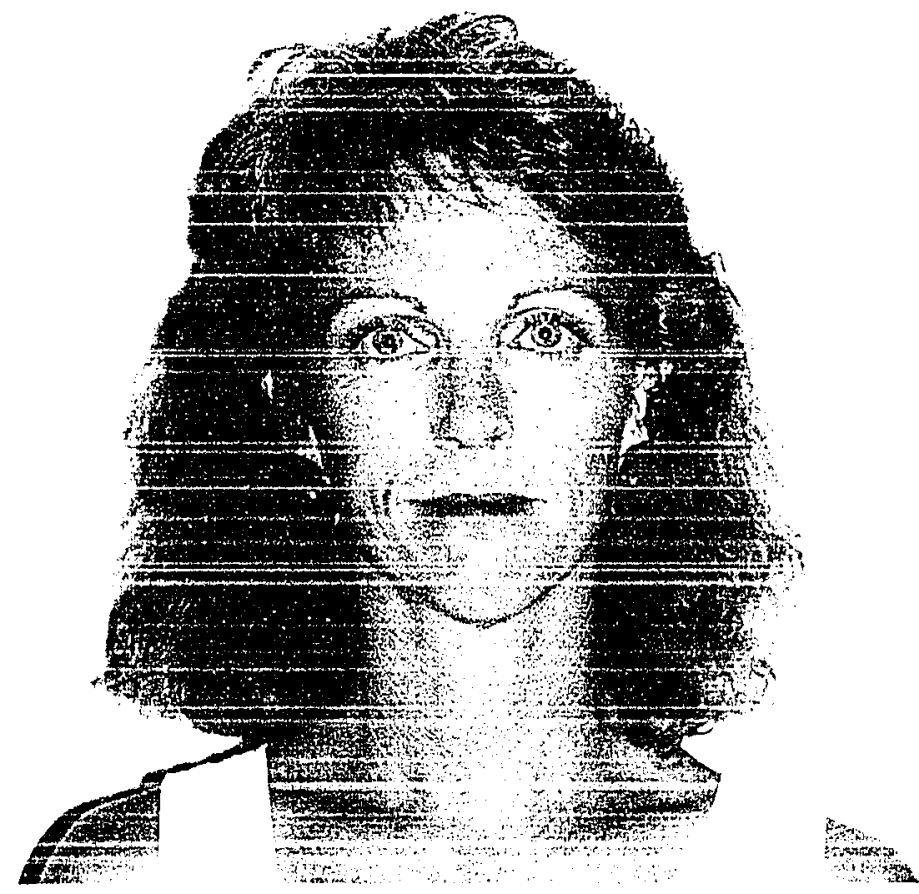


APPENDIX D

REVISED ELDERLY QUESTIONNAIRE 


\section{REVISED ELDERLY QUESTIONNAIRE}

I am a student at San Jose state University, studying communication. We at San Jose state are interested in studying the life satisfaction of older people, and the function of thinking and talking about the past. The information you provide will help us understand more about feelings of self-esteem and life satisfaction in our later years.

Attached is a questionnaire asking you to respond to a series of statements. The only risk involved is that some of the questions might be upsetting, since they ask you to recall past experiences. It only takes about 15 minutes to complete the form. Once you have finished you can return it to the distributor. I want to make sure that you know that your participation in this study is voluntary. You may refuse to participate in this study or in any part of this study, and may withdraw at any time, without prejudice to your possible relations with San Jose state University or the organization where you received this questionnaire. The results from this study may be published, but any information from this study that can be identified with you will remain confidential and will be disclosed only with your separate permission.

If you have any questions about this study, I would be happy to talk with you. I can be reached at (408) 779-5156. Complaints about the procedures may be presented to my advisor, Wen-Shu Lee, Ph.D. at (408) 924-5371. For questions or complaints about research subject's rights, or in the event of research-related injury, contact serena Stanford, Ph.D. (Associate Academic Vice President for Graduate studies \& Research) at (408) 924-2480. I hope you will find the time to help us, so we can learn more about communication and aging.

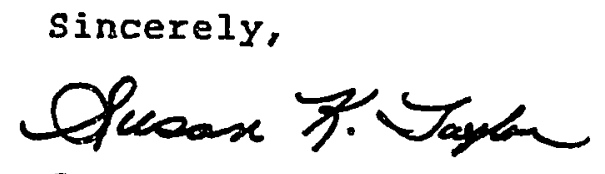

Susan K. Taylor 


\section{PART I}

SEX : MALE FEMALE

AGE :

HHERE DO YOU LIVE? (Please check one) HOUSE - ARARTMENT RETIREMENT VILLAGE CONVALESCENT HOME OTHER (please specify)

ETHNIC BACKGROUND: (Please check only one blank.)

\begin{tabular}{ll}
\hline HISPANIC & \multicolumn{1}{l}{ KOREAN } \\
WHITE & BLACK, AFRICAN AMERICAN \\
\hline JAPANESE & FILIPINO \\
CHINESE & OTHER, NON-WHITE \\
\hline AMERICAN INDIAN & - OTHER
\end{tabular}

PROFESSIONAL BACKGROUND :

(Please $f i l l$ in the blanks.)

ARE YOU CURRENTLY WORKING?

IF YES, WHAT IS YOUR CURRENT OCCUPATION?

ARE YOU RETIRED?

IF YES, WHAT WAS YOUR MAIN OCCUPATION?

PLEASE LIST ANY ORGANIZATIONS IN WHICH YOU ARE CURRENTLY ACTIVE. 
PLEASE NOTE

Copyrighted materials in this document have not been filmed at the request of the author. They are available for consultation, however, in the author's university library.

100-109

University Microfilms International 
110

APPENDIX E

REVISED CATE CODING CATEGORIES AND DEFINITIONS 


\section{REVISED CATE CODING CATEGORIES AND DEFINITIONS \\ Coding sheet for Picture Questions}

QID Why do you think the person you chose is the oldest?

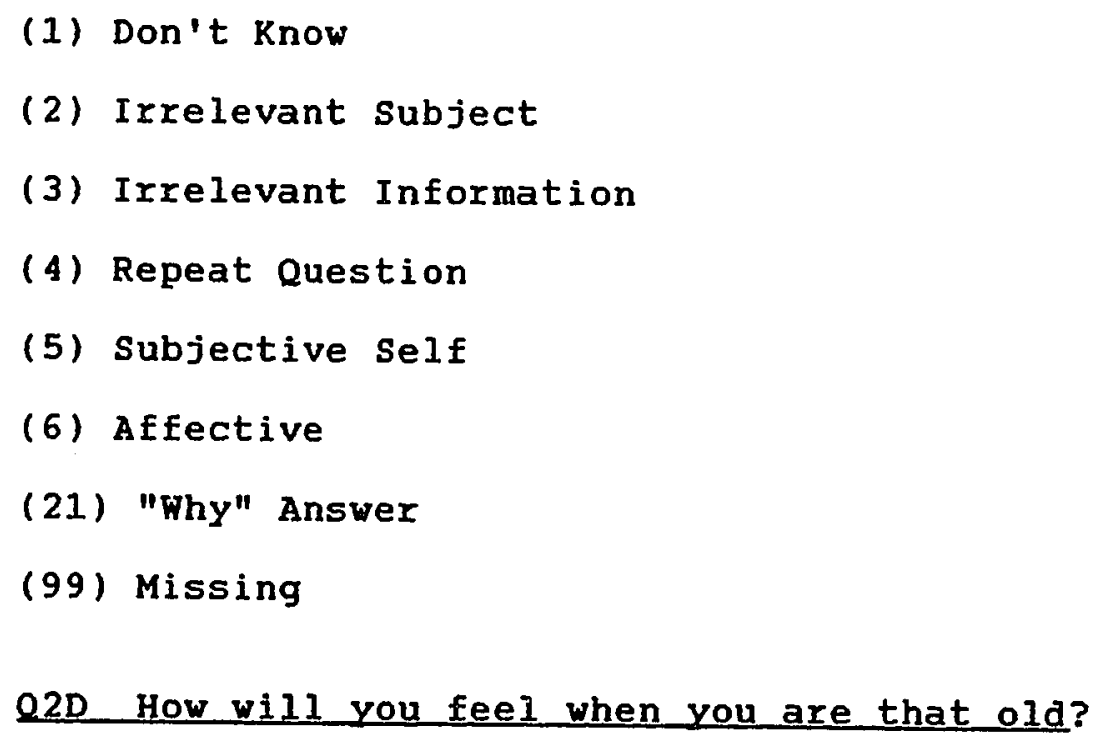

(1) Don't know

(2) Irrelevant subject

(3) Irrelevant Information

(4) Repeat Question

(5) Subjective self

(6) Affective

(21) "Why" Answer

(99) Missing

Q2D How will you feel when you are that old?
(1) Don't know
(2) Irrelevant subject
(3) Irrelevant Information
(4) Repeat Question
(7) Domestic/Work Related Activity
(8) School Oriented Activity
(9) Caretaking Activity
(10) Play Activity
(20) Quasi-Scientific Understanding
(31) Negative Adjective
(32) Positive Adjective
(99) Missing 
Q3D What things would you help this person do?

Q4D What things could she help you do?

(1) Don't know

(2) Irrelevant subject

(3) Irrelevant Information

(4) Repeat Question

(6) Affective

(7) Domestic/Work Related Activity

(8) School oriented Activity

(9) Caretaking Activity

(10) Play Activity

(11) Social Activity

(20) Quasi-scientific Understanding

(23) Role Related

(30) Violent Answer

(99) Missing

Q5A How old do you think each of these women are?

TYPE

(1) Numerical

(2) Verbal

(3) Mixed
DISCRIMINATE

(1) Yes

(2) No
RANGE

G : 56-85

$A: 30-49$

(1) Yes

(2) No 
Q6D Why do you prefer to be with ?

(1) Don't Know

(2) Irrelevant Subject

(3) Irrelevant Information

(4) Repeat Question

(5) Subjective self

(6) Affective

(7) Domestic/Work Related Activity

(8) School Oriented Activity

(9) Caretaking Activity

(10) Play Activity

(11) Social Activity

(13) Discipline

(22) Physical Artifact

(23) Role Related

(24) Age Related

(99) Missing

27D What kinds of things could you do with that person?

Refer to the coding used for QD3\& QD4 
Coding Sheet for Word Association Questions

QIIIA \& QIIIB What old people do you know?

(33) Grandparents and Great grandparents

(34) Other Relatives

(35) older Children (including siblings)

(36) Teachers

(37) Specific Names without Reference to Relation

(38) Acquaintances (eg. neighbor, people they've seen)

QII What do you like to do with that person?

(1) Don't know

(2) Irrelevant subject

(3) Irrelevant Information

(4) Repeat Question

(6) Affective

(7) Domestic/Work Related Activity

(8) School Oriented Activity

(9) Caretaking Activity

(10) Play Activity

(11) Social Activity

(12) Exercise

(23) Role Related

(31) Negative Adjective

(32) Positive Adjective

(99) Missing

QII3D How often do you see this person? 
QII5D Can you give me another name for old people?

(1) Don't Know

(2) Irrelevant subject

(3) Irrelevant Information

(20) Quasi-scientific Understanding

(33) Grandparents and Great grandparents

(34) Other Relatives

(35) Older Children (including siblings)

(36) Teachers

(37) Specific Names Without Reference to Relation

(38) Acquaintances (eg. neighbor, people they've seen)

(99) Missing

QII6D How do you feel about getting old?

(1) Don't know

(2) Irrelevant subject

(3) Irrelevant Information

(4) Repeat Question

(7) Domestic/Work Related Activity

(8) School Oriented Activity

(9) Caretaking Activity

(10) Play Activity

(12) Exercise

(20) Quasi-Scientific Understanding

(31) Negative Adjective

(32) Positive Adjective

(99) Missing 
QII7D What can you tell me about old people?

QII8D what can you tell me about (answer provided in QIIIA $\& Q I I I B I$ ?

(1) Don't know

(2) Irrelevant subject

(3) Irrelevant Information

(4) Repeat Question

(6) Affective

(7) Domestic/Work Related Activity

(8) School Oriented Activity

(9) Caretaking Activity

(10) Play Activity

(11) Social Activity

(12) Exercise

(13) Discipline

(20) Quasi-scientific Understanding

(23) Role Related

(31) Negative Adjective

(32) Positive Adjective

(99) Missing 


\section{Definitions of Categories}

(1) Don't know

(2) Irrelevant Subject

(3) Irrelevant Information

(4) Repeat Question

(5) Subjective Self

(6) Affective
Refers to all responses in which the child is unable to provide an answer. Responses such as "I don't know," "Because," and "I forgot" are considered to fit under this category.

Responses which do not address the the question. The child goes off on a tangent to discuss something else. For example if the question asks, "How do feel about getting old," and the child answers with "I'm going to the park today."

Refers to responses in which the child attempts to answer the specific question, but the response does not provide the type of information which would normally be associated with the question. For example if the questions asks, "Why do you think she's the oldest?", and the child responds with "Because she has a haircut" or Make her happy." Another example would be if the question asks, "What kinds of things would you do with this person?", and the child responds with "I think she should leave."

Refers to responses in which the child rephrases the question without providing any further explanation. For example if the question asks, "Why do you think she's the oldest?", and the child responds with "because she's old."

Refers to responses which indicate personal preference or a sense of confidence in his/her answer. Examples of this would be "Because I chose her," or "I know I'm right."

Responses pertaining to feelings or emotions fall under this category. The child wants to arouse an emotion in the person or the child conveys an emotion about him or herself. Examples of this would be "I want to make her happy," "Make him laugh," or "I like her." 
(7) Domestic/ Work Related Activity

(8) School Oriented Activity

(9) Caretaking Activity

(10) Play Activity

(11) Social Activity

(12) Exercise

(13) Discipline

(20) QuasiScientific Understanding
This category includes responses which describe household chores that the child and the other person do together and work that the older person does. Examples of these type of activities would be cooking, cleaning, vacuuming, carrying groceries, working at the office.

Refers to responses that describe the $k$ ind of learning activities the child partakes in at preschool. Responses such as "study her homework," "Draw pictures," and "Help me cut," would be considered school activities.

Includes responses which describe how the child or the older person is going to help the other with a personal activity. Some caretaking examples would be "Show her how to walk," "Wash her hair," "Give me some food," "Put me to bed," and "Make her feel better."

Responses in which the child states "play" or describes a specific playful activity, such as a game, telling jokes, etc.

Refers to responses in which the child and older person do things together of a social nature. Some examples of social activities would be visiting each other, going to church or restaurants, watching television, and taking the dog for a walk.

Refers to responses that indicate physical exercise other than play. Some examples of exercise would be running, skipping, working out, etc.

Refers to responses in which the child mentions disciplinary actions such as spanking or yelling.

Refers to responses in which the child interprets "old" from a child's perspective instead of an adult's perspective. Examples for this category would be where the child interprets old 
(20) Quasi-

Scientific

Understanding

(continued)

to mean a numerical age older than his

or her age, older children, bigger or

taller, or an activity associated with adults such as smoking, driving, or divorcing.

(21) "Why" Answer

(22) Physical Artifact

Responses to "Why do you think she's the oldest?" in which the child is able to explain correctly the reason behind his or her selection. Examples such as "She has wrinkles," or "She's a grandma," would be considered "Why" Answers.

Refers to responses in which the child answers the question by giving physical descriptions of the person, or what they are wearing, which does not refer age. Examples of artifacts would be jewelry, clothes; or eye color.

(23) Role Related

Responses in which the child assigns the woman to a specific role such as grandma, friend, teacher, or a neighbor.

(24) Age Related

Responses in which the child prefers to be with the woman because she is old or young.

(30) violent

(31) Negative Adjective

This category refers to responses in which the child indicates extreme bodily harm.

Refers to responses which describe someone as "sick," "bad," or "sad."

(32) Positive Adjective

Refers to responses which describe someone as "fine," "good," or "happy" (not the condition of making someone happy).

(99) Missing

No answer recorded 